\title{
Plasma activated electrochemical ammonia synthesis from nitrogen and water
}

\author{
Rakesh K. Sharma ${ }^{a, *}$, Hrishikesh Patel ${ }^{a}$, Usman Mushtaq $^{a}$, Vasileios Kyriakou ${ }^{a}$, Georgios \\ Zafeiropoulos $^{a}$, Floran Peeters ${ }^{a}$, Stefan Welzel ${ }^{a}$, Mauritius C.M. van de Sanden ${ }^{a, b}$, Mihalis N. Tsampas $^{a, *}$
}

${ }^{a}$ Dutch Institute for Fundamental Energy Research (DIFFER), De Zaale 20, 5612 AJ, Eindhoven, the Netherlands

${ }^{b}$ Department of Applied Physics, Eindhoven University of Technology (TU.e), 5600 MB, Eindhoven, the Netherlands

\section{Corresponding Authors}

*Rakesh K. Sharma, Email r.sharma@differ.nl, Mihalis N. Tsampas. Email m.tsampas@differ.nl

\begin{abstract}
Ammonia is an important precursor of fertilizers, as well as a potential carbon-free energy carrier. Nowadays, ammonia is synthesized via the Haber-Bosch process which is capital-and energyintensive process with an immense $\mathrm{CO}_{2}$ footprint. Thus, alternative processes for the sustainable and decentralized ammonia production from $\mathrm{N}_{2}$ and $\mathrm{H}_{2} \mathrm{O}$ using renewable electricity are required. The key challenges for the realization of such processes are the efficient activation of the $\mathrm{N}_{2}$ bond and selectivity towards $\mathrm{NH}_{3}$. In this contribution, we report an all-electric method for sustainable ammonia production from nitrogen and water using a plasma-activated proton conducting solid oxide electrolyser. Hydrogen species produced by water oxidation over the anode are transported through the proton conducting membrane to the cathode where they react with the plasmaactivated nitrogen towards ammonia. Ammonia production rates and faradaic efficiencies up to of $26.8 \mathrm{nmol} \mathrm{NH}_{3} / \mathrm{s} / \mathrm{cm}^{2}$ and $88 \%$, respectively, were achieved.
\end{abstract}


Table of contents

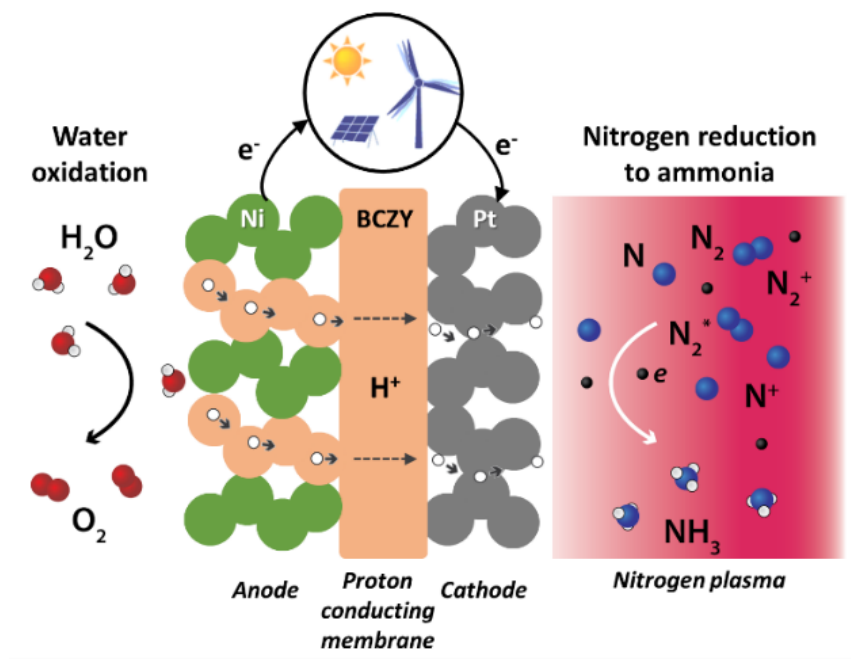

Ammonia, from which virtually all nitrogen-containing compounds are derived, is a major and valuable raw material for industry and agriculture [1-2]. In fact, the fertilizers generated from the ammonia such as ammonium nitrates, phosphates and urea are responsible for sustaining one-third of the Earth's population [3]. Moreover, one mole of ammonia contains $17.6 \mathrm{wt} \%$ of hydrogen (108 $\left.\mathrm{g} \mathrm{H}_{2} / \mathrm{L}\right)$ at $20{ }^{\circ} \mathrm{C}$, which is highly desirable for the transportation [4] as well as for storing intermittent renewable energy such as wind and solar [5-6]. In addition, ammonia has been intensively studied for its potential use as sustainable fuel source [7-8] and other off-grid power applications [9].

Nitrogen-based fertilizer demand is growing rapidly and estimated to show a two or three-folded increase in the second half of the $21^{\text {st }}$ century [10]. To date, approximately 500 million tonnes of ammonia are produced per year via the Haber-Bosch (H-B) process, accounting for 3-5\% of total natural gas consumption worldwide and $2 \%$ of global energy usage $[2,10]$. H-B requires a large fossil fuel energy input, high temperatures $\left(400-600{ }^{\circ} \mathrm{C}\right)$ and pressures $(200-400 \mathrm{~atm})$ as well as a significant capital investment [11-15]. These intense conditions are the main disadvantages of the 
H-B process, as they prevent the possibility of lowering capital costs [16], decentralization and small-scale ammonia production at the level of local communities. Moreover, the world's hydrogen, which is also a key reactant in ammonia production, is produced primarily from the steam reforming of methane, emitting huge amounts of $\mathrm{CO}_{2}$ that account for $1.6 \%$ of global emissions per year $[2,15]$. Therefore, alternative technologies need to be explored for ammonia synthesis, which occur under more moderate conditions [17], require less carbon input [18], or can be powered by intermittent renewable energy sources [19].

Nowadays, plasma technology has attracted a lot of attention as an alternative method of clean ammonia synthesis, including a renewable pathway that coupled this technology with other renewable energy approaches. At low temperature, plasmas are reported as one of the most efficient approaches for rupturing the triple nitrogen bond [20-24], which is the fundamental requirement for the ammonia synthesis. Most of the studies on plasma-assisted ammonia synthesis are based on atmospheric pressure dielectric barrier discharge plasma over various catalytic systems, with nitrogen conversion between $0.2-7.8 \%$ in $\mathrm{N}_{2} / \mathrm{H}_{2}$ mixtures [25-30]. There are also approaches in which plasma activation of nitrogen and water vapor (as a hydrogen source) have been investigated for ammonia synthesis offering promising results in terms of selectivity [31-34]. However, there are a few studies on the synthesis of ammonia from nitrogen-hydrogen using low pressure (0.01-10 Torr) discharges [35-40]. In fact, low pressure nitrogen discharges are wellknown for efficiently producing vibrationally excited molecules that can further generate atomic nitrogen via a vibrational dissociation channel [41-43]. Despite the potential benefits of plasma technologies, such as localized and environmentally friendly energy storage through chemical conversion, the two most critical challenges for upscaling this technology are the efficient dinitrogen fixation and suppression of the reverse reactions. Hence, suitable catalysts with stronger 
plasma synergistic activities and optimized reactor designs are required to overcome these challenges $[45,46]$.

Electrochemical processes for ammonia synthesis have also gathered enormous interest since one can synthesize ammonia directly from water and nitrogen in a single device, thus decreasing the complexity and carbon footprint of the conventional Haber-Bosch process [47-57]. However, the upscaling of this technology is primarily hindered by low rates and/or selectivity (faradaic efficiency) due to the challenge of dinitrogen triple bond cleavage at a rate that is comparable to the hydrogen evolution reaction rate. Recent efforts are directed in the development of more efficient electrode materials or modification of the electrode environment to suppress HER and thus improving faradaic efficiency (FE) towards ammonia synthesis $[55,56]$. The best reported performance in liquid and solid electrolyte electrochemical cells are $\sim 66 \% \mathrm{FE}$ at $6.36 \mathrm{~mA} / \mathrm{cm}^{2}$ $\left(14.5 \mathrm{nmol} / \mathrm{s} / \mathrm{cm}^{2}\right)$ and $\sim 78 \% \mathrm{FE}$ at $1.15 \mathrm{~mA} / \mathrm{cm}^{2}\left(5.6 \mathrm{nmol} / \mathrm{s} / \mathrm{cm}^{2}\right)$ respectively $[55,57]$.

The combination of $\mathrm{N}_{2}$ plasma with electrochemical cells has been recently proposed as an alternative way for nitrogen fixation $[24,58,59]$. In these systems plasma is utilized for nitrogen activation and electrochemical cells for providing the co-reactants. Hawtof et al have reported a hybrid approach where the electrical circuit of the plasma is integrated with the electrolysis one, allowing ammonia synthesis in the absence of nitrogen reduction electrode. FE of this approach has reached values of up to $\sim 100 \%$ at $2.5 \mathrm{~mA}(8.63 \mathrm{nmol} / \mathrm{s}$, the rate is not normalized per surface area due to the electrodeless configuration) [58]. Kumari et al have reported a polymer electrolyte membrane plasma integrated system, where plasma activation leads up to $47 \%$ increase on the ammonia production vs pure electrochemical approach. Due to poor faradaic efficiency the ammonia formation rate was $0.05 \mathrm{nmol} / \mathrm{s} / \mathrm{cm}^{2}$ [59]. 
Inspired by the promising plasma electrochemical integrated systems, we have developed a plasma activated proton conducting solid oxide electrolysis cell (H-SOEC), as shown in Figure 1. At the anode, water oxidation (at anode: $\mathrm{H}_{2} \mathrm{O}(\mathrm{g}) \rightarrow 2 \mathrm{H}^{+}+\frac{1}{2} \mathrm{O}_{2}(\mathrm{~g})+2 e^{-}$) takes place which produces protons $\left(\mathrm{H}^{+}\right)$. These protons are transported to the cathode via proton conducting membrane where they either form molecular hydrogen or react with the activated nitrogen and form the $\mathrm{NH}_{3}$. In this approach, both the reactions (water oxidation and nitrogen reduction to ammonia) are taking place in two different compartments thus allowing two independent knobs of operation. To further understand the potential of the plasma aided electrochemical approach we have benchmarked this pathway with the classical pure plasma (without the presence of catalyst) and plasma assisted catalysis (where both the reactants $\mathrm{H}_{2}$ and $\mathrm{N}_{2}$ are co-injected and co-activated).

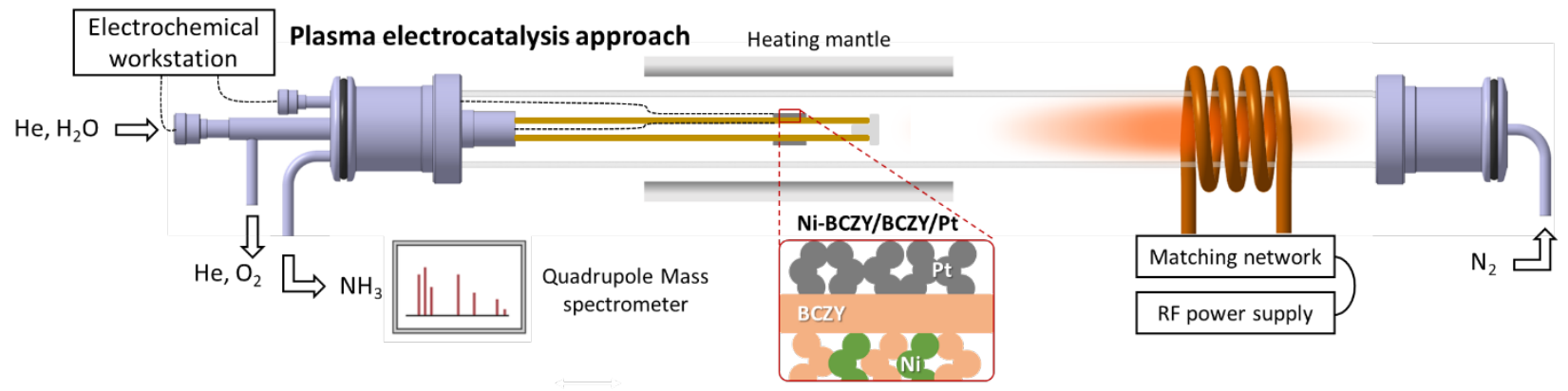

Figure 1: Schematic representation of hybrid plasma electrochemical reactor setup.

Figure 1 shows the schematic of our in-house built reactor to test the $\mathrm{N}_{2}$ plasma-assisted proton conducting solid oxide (H-SOEC) electrolyser. H-SOEC is based on commercial half anode supported cell Ni-BCZY/BCZY (where BCZY is the abbreviation of $\mathrm{BaCe}_{0.2} \mathrm{Zr}_{0.7} \mathrm{Y}_{0.1} \mathrm{O}_{3-\delta}$ ) and a Pt cathode. The microstructure of the Pt catalyst is porous and consists of a network of percolated particles of the order of a micron (Figure S1). Such porous microstructure is desired for efficient diffusion of the reactant gases and for creating high surface area (interfacial area of particle and pore) as well as triple phase boundary (TBP: electrolyte-electrode-gases). 
To determine the role of electrochemical and plasma-assisted electrochemical ammonia synthesis, a transient experiment was carried out at $500^{\circ} \mathrm{C}$ by sequentially varying the applied current (from 0 to $5 \mathrm{~mA}$ ) and the plasma power (from 0 to $80 \mathrm{~W}$ ), as shown in Figure 2. The reactions on each electrode are mentioned below with and without plasma activation.

Anode: $\quad \mathrm{H}_{2} \mathrm{O}(\mathrm{g}) \rightarrow 2 \mathrm{H}^{+}(\mathrm{BCZY})+\frac{1}{2} \mathrm{O}_{2}(\mathrm{~g})+2 e^{-}$

Cathode: $\quad 2 \mathrm{H}^{+}(\mathrm{BCZY})+2 e^{-} \rightarrow \mathrm{H}_{2}(\mathrm{~g})$

$$
6 \mathrm{H}^{+}(\mathrm{BCZY})+\mathrm{N}_{2}(\mathrm{~g})+6 e^{-} \rightarrow 2 \mathrm{NH}_{3}(\mathrm{~g})
$$

Plasma ON: $\quad 3 \mathrm{xH}^{+}(\mathrm{BCZY})+\mathrm{N}_{\mathrm{x}}(\mathrm{g})+3 \mathrm{x} e^{-} \rightarrow \mathrm{xNH}_{3}(\mathrm{~g})$

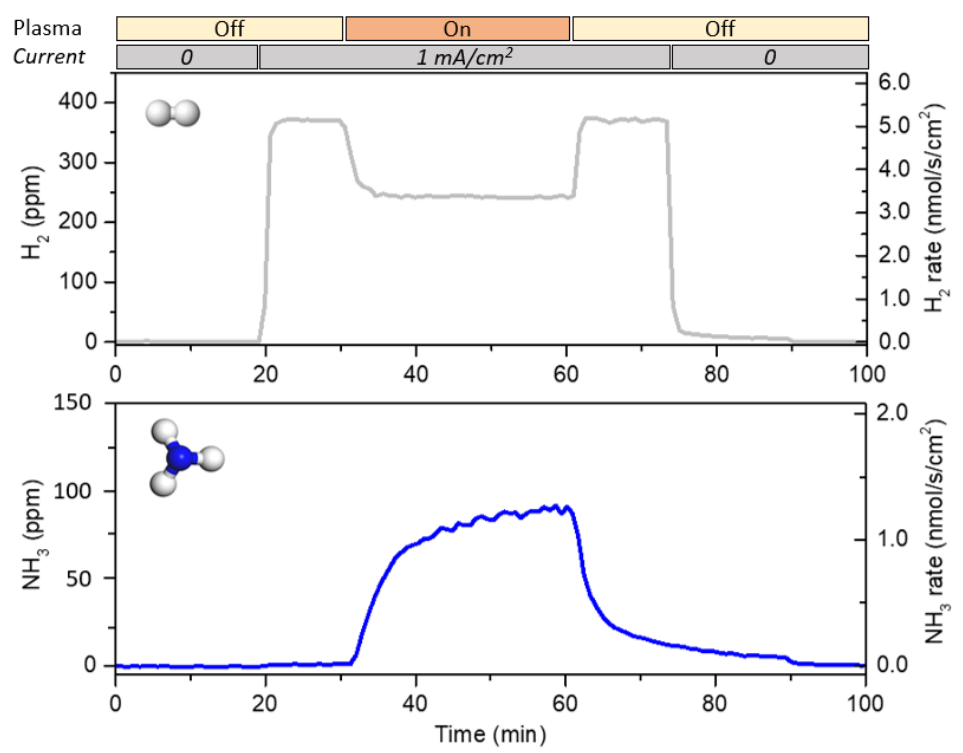

Figure 2: $\mathrm{H}_{2}$ and $\mathrm{NH}_{3}$ production rate $500{ }^{\circ} \mathrm{C}$ upon sequential step changes of the applied current $(5 \mathrm{~mA})$ and plasma $(80 \mathrm{~W})$, respectively.

The rate of $\mathrm{NH}_{3}$ formation under open-circuit $(\mathrm{I}=0)$ and plasma off conditions is zero due to the absence of the hydrogen species on the cathode. Upon applying current (i.e. galvanostatic mode) 
of $5 \mathrm{~mA}$ (at $\mathrm{t}=20 \mathrm{~min}$ ), protons $\left(\mathrm{H}^{+}\right)$from water oxidation (equation 1 ) reach the cathode (via the membrane), forming molecular hydrogen of $\sim 5.14 \mathrm{nmol} \mathrm{H}_{2} / \mathrm{s} / \mathrm{cm}^{2}$ from their associative desorption (equation 2). In the absence of nitrogen plasma activation, no ammonia concentration was detected and this can be attributed to the low operating pressure and the poor electrochemical nitrogen reduction (equation 3) activity of $\mathrm{Pt}$ [60]. Upon plasma ignition (at $\mathrm{t}=30 \mathrm{~min}$ ) in the presence of the same applied current, $\mathrm{NH}_{3}$ formation starts taking place (equation 4) with a simultaneous decrease of the hydrogen evolution and a steady state is reached after $\sim 4$ min. Rate of $\mathrm{NH}_{3}$ production $\left(1.21 \mathrm{nmol} \mathrm{NH} / 3 / \mathrm{s} / \mathrm{cm}^{2}\right)$ is roughly $2 / 3^{\text {rd }}$ the rate of hydrogen consumption $(1.80 \mathrm{nmol}$ $\mathrm{H}_{2} / \mathrm{s} / \mathrm{cm}^{2}$ ), which is consistent with reaction stoichiometry. The corresponding conversion of nitrogen to ammonia is $0.045 \%$ at $1 \mathrm{~mA} / \mathrm{cm}^{2}$ Once plasma is switched off at $\mathrm{t}=60 \mathrm{~min}$, the $\mathrm{NH}_{3}$ production rate gradually returns to zero, while hydrogen formation returns to its initial value and, on further interrupting the current at $\mathrm{t}=73 \mathrm{~min}$, both $\mathrm{NH}_{3}$ and hydrogen signals drop to zero.

Figure 3a shows the current vs. voltage (I-V) curves of proton conducting electrolyser at $500{ }^{\circ} \mathrm{C}$. Under steady-state conditions no electrolysis current is observed, irrespective of plasma conditions (on or off), as expected. The electrolysis current (current density) steadily increased with the applied voltage beyond $1.2 \mathrm{~V}$ which leads to $\mathrm{H}_{2}$ production at the cathode as shown Figure $3 \mathrm{~b}$. With increasing current, $\mathrm{H}_{2}$ production increases as expected. The I-V curves with and without plasma are almost identical. This observation was also verified by the electrochemical impedance spectra (Figure S2) in which the polarization resistance practically remained the same. Therefore, plasma activation does not seem to interfere significantly with charge transfer on the cathode. Moreover, there is no plasma heating impact on the plasma electrode since it is far (i.e. $10-15 \mathrm{~cm}$, defined as plasma afterglow) from the tail of the active plasma zone, as demonstrated in our 
previous work. Thus plasma activation does not have any short-term detrimental effects on the functioning of the electrolyser.

Figures $3 \mathrm{c}$ and $\mathrm{d}$ show the rate of $\mathrm{NH}_{3}$ formation and corresponding faradaic efficiency (i.e. selectivity to ammonia formation) under bias with plasma conditions (80W) as a function of applied current. Upon current application, protons arriving on the Pt/BCZY interface are diffused on the catalyst surface as adsorbates, where they can either react with activated nitrogen species for $\mathrm{NH}_{3}$ formation (equation 3 ) or with co-adsorbed proton species for the formation of molecular hydrogen (equation 2).
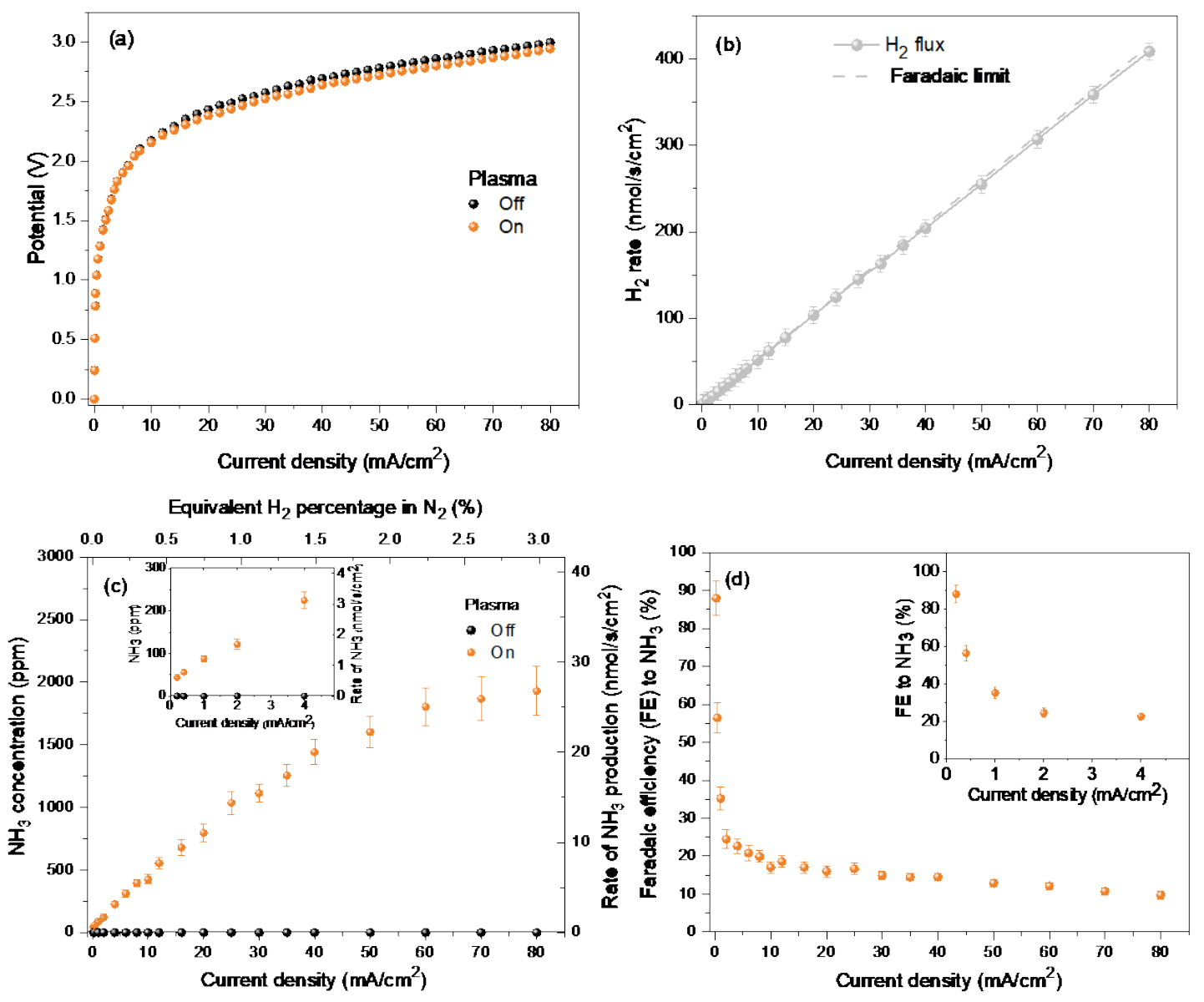
Figure 3: $\mathrm{I}-\mathrm{V}$ characteristics (a), effect of current on the rate of $\mathrm{H}_{2}(\mathrm{~b})$ and $\mathrm{NH}_{3}$ (c) production, faradaic efficiency of $\mathrm{NH}_{3}$ production (d) at $500{ }^{\circ} \mathrm{C}$ and $80 \mathrm{~W}$ plasma power.

At low-current range, production of $\mathrm{NH}_{3}$ increases with the applied current since in this current range, reaction is limited by the supply of hydrogen species (Figure 3c). Whereas at higher current densities, $\mathrm{NH}_{3}$ production keeps increasing but with lower rate. Due to the architecture of our electrode (i.e. porous electronic conducting film with 10 microns thickness deposited on proton conducting support) the reaction zone is extended as the applied current (flux of protons) is increased [61]. At low current densities protons are diffused as adsorbates on the vicinity of the triple phase boundaries (TPB) i.e. electrode (Pt), electrolyte (BSZY) and gas (activated nitrogen) interface. Whereas at high current densities the hydrogen species are diffused to areas further away from the TPB and thus the ammonia production keeps increasing. Faradaic efficiency decreases from $88 \%$ at $0.2 \mathrm{~mA} / \mathrm{cm}^{2}$ to $10 \%$ at $80 \mathrm{~mA} / \mathrm{cm}^{2}$ with increasing current(Figure $3 \mathrm{~d}$ ), suggesting that the vicinity of the TPB is more active for nitrogen fixation when compared to the rest of electrode.

Another important metric in catalytic studies which is not usually reported, is the turnover frequency (TOF) which quantifies the specific activity of a catalytic center by the number of catalytic cycles occurring at the center per unit time. It is usually difficult to define TOF for plasma studies since the quantification of plasma interaction with the reactor walls and/or catalyst is not straightforward. Whereas, in our approach due to the separation of the reactants (via the proton conducting membrane), reaction zone is limited to catalyst surface, which simplifies the estimation of TOF. 
In addition the use of $\mathrm{Pt}$ as cathode has the advantage to offer a reliable way to define the electrochemical active surface area (ECSA). ECSA of Pt can be defined by the well-established method of hydrogen under potential deposition (HUPD) [62]. ECSA of Pt electrode, estimated from HUPD (Figure S3), is equal to $10.5 \mathrm{nmol}$ of Pt per nominal electrode $\mathrm{cm}^{2}$. This allows us to estimate the TOF which is depicted as a function of current density in Figure S4. As one can see value of $\sim 2.6 \mathrm{~s}^{-1}$ is obtained which is quite high when compared with the $\sim 0.1 \mathrm{~s}^{-1}$ of the HaberBosch process [63].

The effect of plasma power, which may affect the distribution of excited states and their flux to the electrocatalyst surface, has also been studied. By estimating plasma volume from the photographs in Figure S5, it is observed that plasma volume increases linearly with power. As shown in the SI, the power density remains constant at approximately $0.6 \mathrm{~W} / \mathrm{cm}^{3}$ in all cases, leading to similar plasma properties for all plasma powers. Therefore, it can be concluded that the largest difference in conditions between different plasma powers comes from the growth of the plasma volume and the corresponding reduction of the distance between the plasma edge and the electrolyser surface. As discussed in the SI, plasma conditions are very similar to those modelled in the work of Guerra et al, who include the development of plasma-activated species downstream of the nitrogen plasma [64]. Assuming a constant axial gas flow velocity between plasma edge and catalyst surface, a time-of-flight for plasma-activated species of $\sim 200 \mathrm{~ms}$ at $40 \mathrm{~W}$ to $\sim 100 \mathrm{~ms}$ at $120 \mathrm{~W}$ has been estimated from the photographs in Figure S5. Comparing with the $\mathrm{N}_{2}$ plasma model by Guerra et al, both vibrationally excited $\mathrm{N}_{2}$ and atomic $\mathrm{N}$ can reach the electrode at significant concentrations. Particularly, highly energetic $\mathrm{N}_{2}(v>10)$ can impinge on the electrolyser at mole fractions of $>10^{-4}$, and atomic nitrogen at mole fractions $>10^{-3}$ and even with higher mole fractions as the plasma edge moves closer to the electrolyser surface [64]. The increase in ammonia 
formation rates with increasing plasma power can, therefore, be assigned to an increasing flux of one or both of these energetic nitrogen species to the electrolyser. As discussed in the SI, the poorer performance at $120 \mathrm{~W}$ compared to $80 \mathrm{~W}$ could be due to a decreased flux of $\mathrm{N}_{2}(v>10)$ to the electrolyser surface, but experimental quantification of the fluxes of energetic nitrogen species will be required before definitive conclusions can be drawn.

Furthermore, pure plasma (without SOEC) and plasma assisted catalysis (with SOEC but at open circuit conditions) have been carried out at $500{ }^{\circ} \mathrm{C}$, where the reactants $\left(\mathrm{H}_{2}\right.$ and $\left.\mathrm{N}_{2}\right)$ were coactivated by RF- plasma, as shown schematically in Figure S6. From Figure 3c-d and S6 (bottom), it is clear that plasma assisted electrochemical approach (1930 ppm NH $3,10 \% \mathrm{H}_{2}$ conversion) is better than either of pure plasma ( $990 \mathrm{ppm} \mathrm{NH}_{3}, 5 \% \mathrm{H}_{2}$ conversion) or plasma assisted catalysis (1185 $\mathrm{ppm} \mathrm{NH}_{3}, 6 \% \mathrm{H}_{2}$ conversion) in terms of rate and hydrogen conversion at $500{ }^{\circ} \mathrm{C}$ and 80 $\mathrm{mA} / \mathrm{cm}^{2}$ current density or equivalent hydrogen. This can be attributed to the different adsorption pathways for hydrogen species involved in each process i.e. via the protonic conducting membrane and gas phases respectively. However, direct comparison between pure plasma and plasma assisted catalysis with electrocatalysis is not straightforward since addition of $\mathrm{H}_{2}$ to the plasma will affect the densities of activated molecules. With the ionization potential (and electron impact ionization cross-sections) being very similar for $\mathrm{N}_{2}$ and $\mathrm{H}_{2}$, the electron density and electron temperature will not change radically when adding $\mathrm{H}_{2}$, but the $\mathrm{N}_{2}(\mathrm{v})$ and $\mathrm{N}$ densities arriving at the catalytic surface may still decrease significantly simply from dilution by $\mathrm{H}_{2}$ [20, 21, 65]. Furthermore, while it has been shown that in pure $\mathrm{N}_{2}$ plasma up to $70 \%$ of electrical power is deposited as internal energy, and up to $35 \%$ specifically in vibrational modes, of the $\mathrm{N}_{2}$ molecule [43]. The addition of $\mathrm{H}_{2}$ will cause a significant fraction of the input power to go towards the internal energy of $\mathrm{H}_{2}$ as well as into dissociation of $\mathrm{H}_{2}$. Especially the latter will reduce $\mathrm{N}$ densities significantly as the $\mathrm{H}_{2}$ content 
increases, since the lower dissociation energy of $\mathrm{H}_{2}(4.5 \mathrm{eV})$ compared to $\mathrm{N}_{2}(9.8 \mathrm{eV})$ will lead to preferential deposition of plasma power into $\mathrm{H}_{2}$ dissociation [66].

Thermodynamic calculations have been also carried out for the equilibrium concentration of $\mathrm{NH}_{3}$ in $\mathrm{N}_{2}, \mathrm{H}_{2}$ and $\mathrm{NH}_{3}$ mixture as a function of temperature and pressure for $3 \% \mathrm{H}_{2}$ in $\mathrm{N}_{2}$ (Figure $\mathrm{S} 7$ ). The performance observed in our approach is $\sim 4$ orders of magnitude higher than the thermodynamic equilibrium at the same temperature and pressure. To realize this difference, a conventional thermochemical reactor operating at thermodynamic equilibrium would require $\sim 100$ bar pressure to produce the same amount of $\mathrm{NH}_{3}$.

To benchmark the performance of our plasma-assisted electrochemical ammonia synthesis reactor with other studies for electrochemical ammonia synthesis (which is based on the similar reactor configuration but without the plasma activation), a comparison to literature for formation rates and faradaic efficiencies to $\mathrm{NH}_{3}$ has been also shown in Figure S8. Typical rate and faradaic efficiencies in this work is higher than reported in the literature for proton conducting solid oxide electrolysers. Overall, achieved ammonia production rates for plasma assisted electrochemical approach is in the range of 0.1 to $2.6 \times 10^{-8} \mathrm{~mol} / \mathrm{s} / \mathrm{cm}^{2}$ with faradaic efficiency varying from 88 to $10 \%$, which is five times lower than required one to satisfy the commercial needs i.e. rate $=10^{-7}$ $\mathrm{mol} / \mathrm{s} / \mathrm{cm}^{2}$ and faradaic efficiency at least 50\% [47]. We believe that these numbers can be achieved with appropriate reactor optimization. To extend our comparison to other electrochemicallydriven systems, we would like to also mention the lithium mediated approaches $[67,68]$. In such systems, faradaic efficiency up to $88.5 \%$ has been reported, which is similar to the efficiency obtained in this work. Nevertheless, the lithium-mediated approaches are multistep processes, whereas in our system the hydrogen production/purification and nitrogen fixation take place in a single step. 
The energy consumption in our system for plasma-assisted electrochemical approach is $605 \mathrm{MJ} / \mathrm{N}$ mol which is within the range of reported values ( 95 to $2698 \mathrm{MJ} / \mathrm{N}-\mathrm{mol}$ ) for $\mathrm{N}_{2}$ fixation by $\mathrm{H}_{2} \mathrm{O}$ [31-33]. However, the reactor in this work demonstrates a proof-of concept for plasma-assisted electrochemical $\mathrm{NH}_{3}$ synthesis with very high formation rate and faradaic conversion. A further reactor optimization is required in order to have more optimized energy consumption and $\mathrm{NH}_{3}$ production. For instance, as mentioned above, the cross-sectional area of the plasma discharge in our setup is much higher than the cross-section/active area of cathode electrocatalyst, due to which most of the activated $\mathrm{N}_{2}$ species bypass the electrocatalyst hence do not contribute in $\mathrm{NH}_{3}$ synthesis. Moreover, Pt cathode electrocatalyst has been used which is highly active for HER kinetics [47-49]. Recent theoretical studies have suggested that a more selective catalyst for nitrogen reduction reaction or with lower hydrogen evolution activity, such as $\mathrm{Co}, \mathrm{Ni}$ and $\mathrm{Ru}$, respectively, could significantly improve the $\mathrm{NH}_{3}$ formation rate $[45,46]$. The effect of electrode microstructure on ammonia production is also essential since porosity, particle size, TPB length, and tortuosity play key role on the accessibility of activated nitrogen and hydrogen species on the reactive sites. Correlation of the microstructural characteristic with ammonia production can only be realized with structured electrode [69]. In future work, these possibilities will be investigated experimentally and combined with plasma modeling for the particular reactor geometry under study here.

To summarize, we have demonstrated that plasma-activated nitrogen can be combined with electrochemically generated surface hydrogen species to achieve an alternative, all electric nitrogen fixation pathway. The highest $\mathrm{NH}_{3}$ production rate is $26.8 \mathrm{nmol} / \mathrm{s} / \mathrm{cm}^{2}$, corresponding to a TOF of $2.6 \mathrm{~s}^{-1}$ at $80 \mathrm{~mA} / \mathrm{cm}^{2}$ with a $10 \%$ faradaic efficiency. Interestingly, at lower current density faradaic efficiency up to $88 \%$ (with rate and TOF of $0.61 \mathrm{nmol} / \mathrm{s} / \mathrm{cm}^{2}$ and $0.059 \mathrm{~s}^{-1}$ 
respectively) was achieved. This novel plasma assisted electrochemical approach was benchmarked and proved superior to the individual pure plasma and plasma catalysis approaches, in which gas phase hydrogen is co-fed and activated with nitrogen by the plasma source. We expect that performance can be further enhanced by improving the interaction of activated nitrogen species with electrocatalyst (via utilization of advanced SOEC architectures and reactor design) and adjusting the operational parameters of the plasma.

\section{ASSOCIATED CONTENT}

\section{Supporting Information}

The Supporting Information is available free of charge on the ACS Publications website at DOI: XXXX. This file contains the experimental, microstructural characterization of NiBCZY/BCZY/Pt cell, Nyquist plot of Ni-BCZY/BCZY/Pt at OCV with and without plasma, active surface area calculation, turn over frequency (TOF) calculation, effect of plasma power on $\mathrm{NH}_{3}$ synthesis, pure plasma and plasma catalysis approaches, equilibrium concentration of ammonia, and benchmarking our approach with electrochemical ammonia synthesis: present study vs literature.

\section{AUTHOR INFORMATION}

\section{Corresponding Authors:}

Rakesh K. Sharma, r.sharma@differ.nl

Mihalis N. Tsampas, m.tsampas@differ.nl, Phone +31403334820 
The authors declare no competing financial interest.

\section{ACKNOWLEDGMENT}

This project has been co-financed by TKI-Energie from Toeslag voor Topconsortia voor Kennis en Innovatie (TKI) from the Ministry of Economic Affairs and Climate Policy. The authors would

like to thank E. Langereis (DIFFER) and B. Lamers (DIFFER) for help with the illustrations and H. Dzafic (TU.e) for his contribution in completing the setup. ISPT, University of Twente, Nouryon, OCI Nitrogen, Vopak and Yara are also acknowledged for their support in the project.

\section{REFERENCES}

[1] Good, A. Toward nitrogen-fixing plants. Science 2018, 359, 869-870.

[2] Wang, K.; Smith, D; Zheng, Y. Electron-driven heterogeneous catalytic synthesis of ammonia: current states and perspective. Carbon Resources Conversion 2018, 1(1), 2-31.

[3] Fryzuk, M. D. Ammonia transformed. Nature 2004, 427, 498-499.

[4] Miura, D.; Tezuka, T. A comparative study of ammonia energy systems as a future energy carrier, with particular reference to vehicle use in Japan. Energy 2014, 68, 428-436.

[5] Demirci, U.B.; Miele, P. Sodium borohydride versus ammonia borane, in hydrogen storage and direct fuel cell applications. Energy Environ. Sci. 2009, 2 (6), 627-637.

[6] Lan, R.; Irvine, J. T.; Tao, S. Ammonia and related chemicals as potential indirect hydrogen storage materials. Int. J. Hydrogen Energy 2012,37 (2), 1482-1494.

[7] Zamfirescu, C.; Dincer, I. Ammonia as a Green Fuel and Hydrogen Source for Vehicular Applications. Fuel Process. Technol. 2009, 90, 729-737. 
[8] Maffei, N.; Pelletier, L.; Charland, J. P.; McFarlan, A. A direct ammonia fuel cell using barium cerate proton conducting electrolyte doped with gadolinium and praseodymium. Fuel Cell. 2007, 7(4), 323-328.

[9] Davis, B.L.; Dixon, D. A.; Garner, E. B.; Gordon, J. C.; Matus, M. H.; Scott, B.; Stephens, F. H. Efficient regeneration of partially spent ammonia borane fuel. Angew. Chem. Int. Ed. 2009, 48 (37), 6812-6816.

[10] Erisman, J.W.; Sutton, M.A.; Galloway, J.; Klimont, Z.; Winiwarter, W. How a century of ammonia synthesis changed the world, Nat. Geosci. 2008, 1, 636-639.

[11] Hargreaves, J. Nitrides as ammonia synthesis catalysts and as potential nitrogen transfer reagents. Appl. Petrochem. Res. 2014, 4 (1), 3-10.

[12] Appl, M. in Ullmann's Encyclopedia of Industrial Chemistry; Wiley, 2012, 3, 107-225.

[13] Schlogl, R. in Handbook of Heterogeneous Catalysis (Eds.: G. Ertl, H. Knözinger, F. Schüth, J. Weitkamp), Wiley-VCH Verlag GmbH \& Co. KGaA, Weinheim, 2008, 25012575.

[14] Smil, V. Enriching the Earth: Fritz Haber, Carl Bosch, and the Transformation of World Food Production; MIT Press, 2004, 1-358.

[15] Liu, H. Ammonia synthesis catalyst 100 years: practice, enlightenment and challenge, Chin. J. Catal. 2014, 35, 1619-1640.

[16] Gilland, B. Is a haber-bosch world Sustainable? Population, nutrition, cereals, nitrogen and environment. J. Soc. Polit. Econ. Stud. 2014, 39 (2), 166-185. 
[17] Vojvodic, A.; Medford, A.J.; Studt, F.; Abild-Pedersen, F.; Khan, T.S.; Bligaard, T.; Nørskov, J.K. Exploring the limits: a low-pressure, low-temperature Habere Bosch process. Chem. Phys. Lett. 2014, 598, 108-112.

[18] Gilbert, P.; Alexander, S.; Thornley, P.; Brammer, J. Assessing economically viable carbon reductions for the production of ammonia from biomass gasification. J. Clean. Prod. 2014, $64,581-589$.

[19] Bardi, U.; El Asmar, T.; Lavacchi, A.Turning electricity into food: the role of renewable energy in the future of agriculture. J. Clean. Prod. 2013, 53, 224-231.

[20] Bogaerts, A.; Neyts, E. C. Plasma Technology: An Emerging Technology for Energy Storage. ACS Energy Lett. 2018, 3, 1013-1027.

[21] Fridman, A. Plasma Chemistry; Cambridge University Press, 2008, 355-414.

[22] Utz, A. L. Vibrations that live long and prosper. Nat. Chem. 2018, 10, 577-578.

[23] Mehta, P.; Barboun, P.; Go, D. B.; Hicks, J. C.; Schneider, W. F. Catalysis Enabled by Plasma Activation of Strong Chemical Bonds: A Review. ACS Energy Lett. 2019, 4 (5), $1115-1133$.

[24] Patel, H.; Sharma , R. K.; Kyriakou, V.; Pandiyan, A.; Welzel, ,S.; van de Sanden, ,M. C.M.; Tsampas, M. N. ACS Energy Letters 2019, 4 (9), 2091-2095.

[25] Neyts, E. C.; Ostrikov, K.; Sunkara, M. K.; Bogaerts, A. Plasma Catalysis: Synergistic Effects at the Nanoscale. Chem. Rev. 2015, 115, 13408-13446.

[26] Patil, B. S.; Van Kaathoven, A. S.; Peeters, F. J.; Cherkasov, N.; Lang, J.; Wang, Q.; Hessel, V. Deciphering the synergy between plasma and catalyst support for ammonia 
synthesis in a packed dielectric barrier discharge reactor. Journal of Physics D: Applied Physics 2020, 53(14), 144003.

[27] Gomez-Ramirez, A.; Cotrino, J.; Lambert, R.; Gonzalez-Elipe, A. Efficient Synthesis of Ammonia from $\mathrm{N}_{2}$ and $\mathrm{H}_{2}$ Alone in a Ferroelectric Packed-bed DBD Reactor. Plasma Sources Sci. Technol. 2015, 24, 065011.

[28] Aihara, K.; Akiyama, M.; Deguchi, T.; Tanaka, M.; Hagiwara, R.; Iwamoto, M. Remarkable Catalysis of a Wool-like Copper Electrode for $\mathrm{NH}_{3}$ Synthesis from $\mathrm{N}_{2}$ and $\mathrm{H}_{2}$ in Non-Thermal Atmospheric Plasma. Chem. Commun. 2016, 52, 13560-13563.

[29] Akay, G.; Zhang, K. Process Intensification in Ammonia Synthesis Using Novel Co assembled Supported Microporous Catalysts Promoted by Nonthermal Plasma. Ind. Eng. Chem. Res.2017, 56, 457-468.

[30] Peng, P.; Chen, P.; Schiappacasse, C.; Zhou, N.; Anderson, E.; Chen, D.; Liu, J.; Cheng, Y.; Hatzenbeller, R.; Addy, M.; Zhang, Y. A review on the non-thermal plasma-assisted ammonia synthesis Technologies. Journal of Cleaner Production 2018, 177, 597-609.

[31] Harada, K.; Igari, S.; Takasaki, M.; Shimoyama, A. Reductive fixation of molecular nitrogen by glow discharge against water. Journal of the Chemical Society, Chemical Communications 1986, 17, 1384-1385.

[32] Bian, W.; Shi, J.; Yin, X. Nitrogen fixation into water by pulsed high-voltage discharge. IEEE Trans. Plasma Sci. 2009, 37 (1), 211- 218.

[33] Gorbanev, Y.; Vervloessem, E.; Nikiforov, A.; Bogaerts, A. Nitrogen Fixation with Water Vapor by Nonequilibrium Plasma: toward Sustainable Ammonia Production. ACS Sustainable Chemistry \& Engineering 2020, 8(7), 2996-3004. 
[34] Toth, J.R.; Abuyazid, N.H.; Lacks, D.J., Renner, J.N.; Sankaran, R.M. A plasma-water droplet reactor for process-intensified, continuous nitrogen fixation at atmospheric pressure. ACS Sustainable Chemistry \& Engineering 2020, 8(39), 14845-14854.

[35] Matsumoto, O. Plasma Catalytic Reaction in Ammonia Synthesis in the Microwave Discharge. J. Phys. IV 1998, 8, 7-411.

[36] Uyama, H.; Nakamura, T.; Tanaka, S.; Matsumoto, O. Catalytic Effect of Iron Wires on the Syntheses of Ammonia and Hydrazine in a Radio-Frequency Discharge. Plasma Chem. Plasma Process. 1993, 13, 117-131.

[37] Shah, J.; Wang, W.; Bogaerts, A.; Carreon, M. L. Ammonia synthesis by radio frequency plasma catalysis: revealing the underlying mechanisms. ACS Applied Energy Materials 2018, 1 (9), 4824-4839.

[38] Shah, J.; Wu. Ting; Lucero, J.; Carreon , M. A.; Carreon , M.L. Nonthermal Plasma Synthesis of Ammonia over Ni-MOF-74, ACS Sustainable Chem. Eng. 2019, 7, 1, 377383.

[39] Van Helden, J.; Wagemans, W.; Yagci, G.; Zijlmans, R.; Schram, D.; Engeln, R.; Lombardi, G.; Stancu, G.; Röpcke, J. Detailed Study of the Plasma-Activated Catalytic Generation of Ammonia in $\mathrm{N}_{2}-\mathrm{H}_{2}$ Plasmas. J. Appl. Phys. 2007, 101, 043305-043316.

[40] Carrasco, E.; Jiménez-Redondo, M.; Tanarro, I.; Herrero, V. J. Neutral and ion chemistry in low pressure dc plasmas of $\mathrm{H}_{2} / \mathrm{N}_{2}$ mixtures: routes for the efficient production of $\mathrm{NH}_{3}$ and $\mathrm{NH}_{4}{ }^{+}$. Physical Chemistry Chemical Physics 2011, 13(43), 19561-19572. 
[41] Gorse, C.; Cacciatore, M.; Capitelli, M.; De Benedictis, S.; Dilecce, G. Electron energy distribution functions under $\mathrm{N}_{2}$ discharge and post-discharge conditions: a self-consistent approach. Chem. Phys. 1988, 119, 63-70.

[42] Ricard, A.; Sarrette, J. P.; Jeon, B.; Kim, Y. K. Discharge source dependent variation in the densities of active species in the flowing afterglows of $\mathrm{N}_{2} \mathrm{RF}$ and UHF plasmas. Curr. Appl. Phys. 2017, 17, 945-950.

[43] Guerra, V.; Galiaskarov, E.; Loureiro, J. Dissociation mechanisms in nitrogen discharges. Chemical physics letters 2003, 371(5-6), 576-581.

[44] Gatti, N.; Ponduri, S.; Peeters, F.J.J.; Van Den Bekerom, D.C.M.; Minea, T.; Tosi, P.; van de Sanden, M.C.M.; Van Rooij, G.J. Preferential vibrational excitation in microwave nitrogen plasma assessed by Raman scattering. Plasma Sources Science and Technology 2018, 27(5), 055006-055028.

[45] Mehta, P.; Barboun, P.; Herrera, F. A.; Kim, J.; Rumbach, P.; Go, D. B.; Hicks, J. C.; Schneider, W. F. Overcoming ammonia synthesis scaling relations with plasma-enabled catalysis. Nat. Catal. 2018, 1, 269-275.

[46] Barboun, P.; Mehta, P.; Herrera, F. A.; Go, D. B.; Schneider, W. F.; Hicks, J. C. Distinguishing Plasma Contributions to Catalyst Performance in Plasma-Assisted Ammonia Synthesis, ACS Sustainable Chem. Eng. 2019, 7, 9, 8621-8630.

[47] Giddey, S.; Badwal, S.P.S.; Kulkarni, A. Review of electrochemical ammonia production technologies and materials. Inter. J Hydrogen Energy 2013, 38, 14576-14594.

[48] Amar, I.A.; Lan, R.; Petit, C.T.; Tao, S.W. Solid-state electrochemical synthesis of ammonia: a review. J. Solid State Electrochem. 2011,15, 1845-1860. 
[49] Kyriakou, V.; Garagounis, I.; Vasileiou, E.; Vourros, A.; Stoukides, M. Progress in the Electrochemical Synthesis of Ammonia, Catalysis Today 2017, 286, 2-13.

[50] Ohrelius, M.; Guo, H.; Xian, H.; Yu, G.; Alshehri, A. A.; Alzahrani, K.A.; Li, T.; Andersson, M. Electrochemical Synthesis of Ammonia Based on a Perovskite $\mathrm{LaCrO}_{3}$ Catalyst, ChemCatChem 2020, 12.3, 731-735.

[51] Soloveichik, G. Electrochemical synthesis of ammonia as a potential alternative to the Haber-Bosch process. Nature Catalysis 2019, 2(5), 377-380.

[52] Kyriakou, V.; Garagounis, I.; Vourros, A.; Vasileiou, E.; Stoukides, M. An Electrochemical Haber-Bosch Process, Joule 2020, 4, 1-17.

[53] Amar, I. A.; Petit, C. T.; Mann, G.; Lan, R.; Skabara, P. J.; Tao, S. Electrochemical synthesis of ammonia from $\mathrm{N}_{2}$ and $\mathrm{H}_{2} \mathrm{O}$ based on $(\mathrm{Li}, \mathrm{Na}, \mathrm{K})_{2} \mathrm{CO}_{3}-\mathrm{Ce}_{0.8} \mathrm{Gd}_{0.18} \mathrm{Ca}_{0.02} \mathrm{O}_{2-\delta}$ composite electrolyte and $\mathrm{CoFe}_{2} \mathrm{O}_{4}$ cathode. Int. J. Hydrogen Energy 2014, 39, 4322-4330.

[54] Lan, R.; Alkhazmi, K. A.; Amar, I. A.; Tao, S. Synthesis of ammonia directly from wet air using new perovskite oxide $\mathrm{La}_{0.8} \mathrm{Cs}_{0.2} \mathrm{Fe}_{0.8} \mathrm{Ni}_{0.2} \mathrm{O}_{3-\delta}$ as catalyst. Electrochim. Acta 2014, $123,582-587$.

[55] Hao, Y.C.; Guo, Y.; Chen, L.W.; Shu, M.; Wang, X.Y.; Bu, T.A.; Gao, W.Y.; Zhang, N.; $\mathrm{Su}, \mathrm{X}$.; Feng, X; Zhou, J.W. Promoting nitrogen electroreduction to ammonia with bismuth nanocrystals and potassium cations in water. Nature Catalysis 2019, 2(5), 448-456.

[56] Zhou, F.L.; Azofra, L.M.; Ali, M.; Kar M.; Simonov, A.N.; McDonnell-Worth, C.; Sun, C.; Zhang, Z.; R. MacFarlane, D.R. Electro-synthesis of ammonia from nitrogen at ambient temperature and pressure in ionic liquids. Energy Environ. Sci. 2017, 10, 2516-2520 
[57] Marnellos, G.; Stoukides, M. Ammonia synthesis at atmospheric pressure. Science 1998, $282,98-100$.

[58] Hawtof, R.; Ghosh, S.; Guarr, E.; Xu, C.; Sankaran, R. M.; Renner, J. N. Catalyst-free, highly selective synthesis of ammonia from nitrogen and water by a plasma electrolytic system. Sci. Adv. 2019, 5, 5778-5788.

[59] Kumari, S.; Pishgar, S.; Schwarting, M.E.; Paxton, W.F.; Spurgeon, J.M. Synergistic plasma-assisted electrochemical reduction of nitrogen to ammonia. Chemical communications 2018, 54(95), 13347-13350.

[60] Skulason, E.; Bligaard, T.; Gudmundsdottir, S.; Studt, F.; Rossmeisl, J.; Abild-Pedersen, F.; Vegge, T.; Jónsson, H.; Nørskov, J. K. A theoretical evaluation of possible transition metal electro-catalysts for $\mathrm{N}_{2}$ reduction. Phys. Chem. Chem. Phys. 2012, 14, 1235-1245.

[61] Vernoux, P.; Lizarraga, L.; Tsampas, M.N.; Sapountzi, F.M.; De Lucas-Consuegra, A.; Valverde, J.L.; Souentie, S.; Vayenas, C.G.; Tsiplakides, D.; Balomenou, S.; Baranova, E. Ionically conducting ceramics as active catalytic supports. Chemical Reviews 2013, $113(10), 8192-8260$.

[62] Łukaszewski, M.; Soszko, M.; Czerwinski, A. Electrochemical methods of real surface area determination of noble metal electrodes-an overview. Int. J. Electrochem. Sci. 2016, $11,4442-4469$.

[63] Ogura, Y.; Sato, K.; Miyahara, S.I.; Kawano, Y.; Toriyama, T.; Yamamoto, T.; Matsumura, S.; Hosokawa, S.; Nagaoka, K. Efficient ammonia synthesis over a $\mathrm{Ru} / \mathrm{La}_{0.5} \mathrm{Ce}_{0.5} \mathrm{O}_{1.75}$ catalyst pre-reduced at high temperature. Chemical science $2018,9(8)$, 2230-2237. 
[64] Guerra, V.; Sá, P. A.; Loureiro, J. Electron and metastable kinetics in the nitrogen afterglow. Plasma sources science and technology 2003, 12(4), S8-S15.

[65] Amorim, J.; Baravia, G.; Ricard, A. Production of N, H, and $\mathrm{NH}$ active species in $\mathrm{N}_{2}-\mathrm{H}_{2}$ dc flowing discharges. Plasma Chemistry and Plasma Processing 1995, 15(4), 721-731.

[66] Gordiets, B.; Ferreira, C.M.; Pinheiro, M.J.; Ricard, A. Self-consistent kinetic model of low-pressure N2-H2 flowing discharges: I. Volume processes. Plasma Sources Sci. Technol. 1998, 7,363-378.

[67] Lazouski, N.; Chung, M.; Williams, K.; Gala, M.L.; Manthiram, K. Non-aqueous gas diffusion electrodes for rapid ammonia synthesis from nitrogen and water-splitting-derived hydrogen. Nature Catalysis 2020, 3(5), 463-469.

[68] McEnaney, J.M.; Singh, A.R.; Schwalbe, J.A.; Kibsgaard, J.; Lin, J.C.; Cargnello, M.; Jaramillo, T.F.; Nørskov, J.K. Ammonia synthesis from $\mathrm{N}_{2}$ and $\mathrm{H}_{2} \mathrm{O}$ using a lithium cycling electrification strategy at atmospheric pressure. Energy \& Environmental Science 2017, 10(7), 1621-1630.

[69] Papaioannou E.I.; Bachmann, C.; Neumeier, J.J.; Frankel, D.; Over, H.; Janek, J.; Metcalfe, I.A. Role of the Three-Phase Boundary of the Platinum-Support Interface in Catalysis: A Model Catalyst Kinetic Study, ACS Catalysis 2016, 6, 9, 5865-5872. 


\title{
Supporting Information
}

\section{Plasma Activated Electrochemical Ammonia Synthesis from Nitrogen and water}

\author{
Rakesh K. Sharma ${ }^{a} *$, Hrishikesh Patel ${ }^{a}$,Usman Mushtaq ${ }^{a}$, Vasileios Kyriakou ${ }^{a}$, Georgios \\ Zafeiropoulos $^{a}$, Floran Peeters $^{a}$, Stefan Welzel ${ }^{a}$, Mauritius C.M. van de Sanden ${ }^{a, b}$, Mihalis N. Tsampas ${ }^{a, *}$
}

aDutch Institute for Fundamental Energy Research (DIFFER), De Zaale 20, 5612 AJ, Eindhoven, the Netherlands

${ }^{\text {b}}$ Department of Applied Physics, Eindhoven University of Technology (TU.e), 5600 MB, Eindhoven, the Netherlands

Corresponding Author

*Rakesh K. Sharma, Email r.sharma@differ.nl, Mihalis N. Tsampas. Emailm.tsampas@differ.nl 


\section{EXPERIMENTAL}

\section{Set-up description}

Schematic of our in-house built reactor to test the $\mathrm{N}_{2}$ plasma-assisted proton conducting solid oxide (H-SOEC) electrolyzer, is shown in Figure 1. As mentioned, it is characterized by a RF plasma source and a proton conducting solid oxide electrolysis cell (H-SOEC), which operates in intermediate temperature range $\left(400-650^{\circ} \mathrm{C}\right)$. Reactor consists of an inductive coil which is connected to the matching network of a RF power supply (Huttinger PFG 300 RF:13.56 MHz, 300

$\mathrm{W}$ maximum power rating). The inductive coil encloses a quartz tube (40 $\mathrm{mm}$ outer diameter and $700 \mathrm{~mm}$ length), mounted on vacuum flanges on both ends. These flanges also serve as mechanical support for both the quartz tube and the tubular proton conducting solid oxide electrolysis cell (HSOEC). H-SOEC is based on commercial half anode supported cell (Coorstek: Ni-BCZY/BCZY, where $\mathrm{BCZY}$ is the abbreviation of $\left.\mathrm{BaCe}_{0.2} \mathrm{Zr}_{0.7} \mathrm{Y}_{0.1} \mathrm{O}_{3-\delta}\right)$ on which cathode $(\mathrm{Pt})$ was deposited by brush painting. Inner volume of the tubular H-SOEC (anode side) is referred as inner compartment whereas the active and passive zone of the plasma (cathode side) in the quartz tube is referred as plasma compartment. For each compartment, there is one inlet and one outlet. Outlets of each compartment is connected with a Quadrupole Mass Spectrometer (HAL 201RC) whereas inlets of inner comportment of H-SOEC and plasma compartment are connected to humidified He and $\mathrm{N}_{2}$ supply (Figure 1), respectively.

As depicted in the inset of Figure 1, the inner electrode serves as the anode (counter-electrode) while the outer as an cathode (working electrode; plasma-electrode). Humidified He (50 sccm) is fed in the inner compartment (1 bar) of the tubular cell while $\mathrm{N}_{2}(100 \mathrm{sccm})$ is used as feed gas in the plasma compartment ( 5 mbar). The gas temperature is assumed to be as furnace temperature since the plasma itself will not give much heating at this low pressure. The plasma excitation was 
started when the hydrogen in plasma compartment reached in steady state and furnace at desired temperature.

\section{Electrolyzer preparation}

$\mathrm{Ni}-\mathrm{BCZY} / \mathrm{BCZY} / \mathrm{Pt}$ proton conducting solid oxide electrolyser (H-SOEC) was prepared by brush painting the Pt plasma electrode (cathode) on the outer surface of a commercial anode-supported half-cell (Coorstek: Ni-BCZY/BCZY tube). Cathode was fabricated by calcining the Pt paste (organometallic paste, Fuel Cell Materials) at $650{ }^{\circ} \mathrm{C}$ for $2 \mathrm{~h}$ in ambient air. Prior to the experiments, the Pt electrocatalyst was reduced in $5 \% \mathrm{H}_{2} / \mathrm{He}$ for $1 \mathrm{~h}$ at $650{ }^{\circ} \mathrm{C}$. The superficial plasma electrode surface area is $5 \mathrm{~cm}^{2}$ with a loading of $\sim 5 \mathrm{mg} / \mathrm{cm}^{2}$. Ni and Au wires were used as the anode and the cathode current collectors, respectively.

\section{Characterization}

The surface morphology and cross-section of the Ni-BCZY/BCZY/Pt were characterized using a scanning electron microscope (FEI Quanta 3D FEG instrument). Electrochemically active surface area (ECSA) of Pt was estimated by the well-established method of hydrogen under potential deposition (HUPD). The electrochemical characterization was carried out using a CompactStat (Ivium) potentiostat. The experiments were performed at $500{ }^{\circ} \mathrm{C}$ for three different values of applied input power $(40-120 \mathrm{~W})$ while maintaining $0 \mathrm{~W}$ reflected power through a tunable matching network. The gases from the electrochemical cell and plasma reactor were analyzed using a Hiden Analytical Quadrupole Mass Spectrometer HAL 201RC. 


\section{Quantification of ammonia and equilibrium concentrations}

Quantification of as synthesized $\mathrm{NH}_{3}$ and production /consumption of $\mathrm{H}_{2}$ was carried out by calibrating them using $200 \mathrm{ppm} \mathrm{NH}_{3}$ in $\mathrm{He}$ and $1 \% \mathrm{H}_{2}$ in He cylinders , respectively. In each case, the standard gas mixture was diluted further with He in the levels of $50 \%$ and $20 \%$ keeping the flow rate constant. In both cases $\left(\mathrm{H}_{2}\right.$ and $\left.\mathrm{NH}_{3}\right)$, a linear relation between the signal level of the calibrating gas and the gas examined, was observed. To validate that ammonia in our system is actually produced by $\mathrm{N}_{2}$ reduction, we quantitively compare the decrease in $\mathrm{H}_{2}$ signal with the increase in $\mathrm{NH}_{3}$ 's. In all cases, the observed alterations of the corresponding concentrations were in good agreement with a relative error of $4 \%$. Due to the sticky nature of ammonia molecule (and the length of the sampling line) the equilibration time during mass spectrometer measurements was 30 min. We have also performed blank experiments where the $\mathrm{N}_{2}$ feed gas was substituted with Ar. In these experiments, no ammonia production was detected, further verifying the clarity of the presented results. To estimate the equilibrium concentration of $\mathrm{NH}_{3}$ in a $\mathrm{N}_{2}, \mathrm{H}_{2}$ gas mixture the HSC Chemistry software (Outotec Technologies) was used.

\section{Energy consumption calculations}

The plasma power $\left(\mathrm{P}_{\mathrm{P}}\right)$ levels indicated in the study concern power transferred to the coil, as indicated on the power supply, since the reflected power is always tuned to zero. However, an unknown fraction of this power is absorbed by the plasma, with the remainder being radiated into free space by the coil. The fraction of this power absorbed in the plasma is difficult to determine in our system, so for our energy consumption calculations we assumed that all the power is dissipated in the plasma. It can be stated that the actual fraction of absorbed power is likely a constant in the experiment, because electrical plasma properties (i.e. electron density, reduced 
electric field) remain constant with increasing power, so that the coupling between coil and plasma can also be expected to remain constant. This is supported by the observation that the plasma volume increases linearly with the power setting on the power supply, as discussed in the section on the effect of plasma power on $\mathrm{NH}_{3}$ synthesis below.

The power consumed for the SOEC operation $\left(\mathrm{PSOEC}_{\mathrm{S}}\right)$ is defined as $\mathrm{V} * \mathrm{I}$, where $\mathrm{V}$ is applied voltage and I is resulting current. At the maximum plasma aided electrochemical ammonia synthesis $\mathrm{PSOEC}_{\mathrm{S}}$ $=2.75 \mathrm{~V} \times 0.4 \mathrm{~A}=1.1$ and plasma power $(\mathrm{PP}=80 \mathrm{~W})$, ammonia production rate is maximum. Under these conditions, the ammonia production rate is $26.8 \mathrm{nmol} / \mathrm{s} / \mathrm{cm}^{2}$ (or $134 \mathrm{nmol} / \mathrm{s}$ ). The energy consumption $(\mathrm{EC})$ is calculated as: $\mathrm{EC}(\mathrm{J} / \mathrm{mol})=($ Total power $(\mathrm{W})) /(\operatorname{ammonia}$ rate $(\mathrm{mol} / \mathrm{s}))$ Under above mentioned conditions, $\mathrm{EC}$ is $605 \mathrm{MJ} / \mathrm{N}-\mathrm{mol}$. 


\section{RESULTS}

\section{Microstructural Characterization}

Figure $\mathrm{S} 1$ shows microstructure of the Ni-BCZY/BCZY /Pt cell, the electrode thickness is around $10 \mu \mathrm{m}$. Electrode has a porous structure and consists of a network of percolated particles of the order of micron. SEM micrographs before and after plasma experiments show no difference due to the mild conditions of our plasma and the distance of the active zone with the cathode.
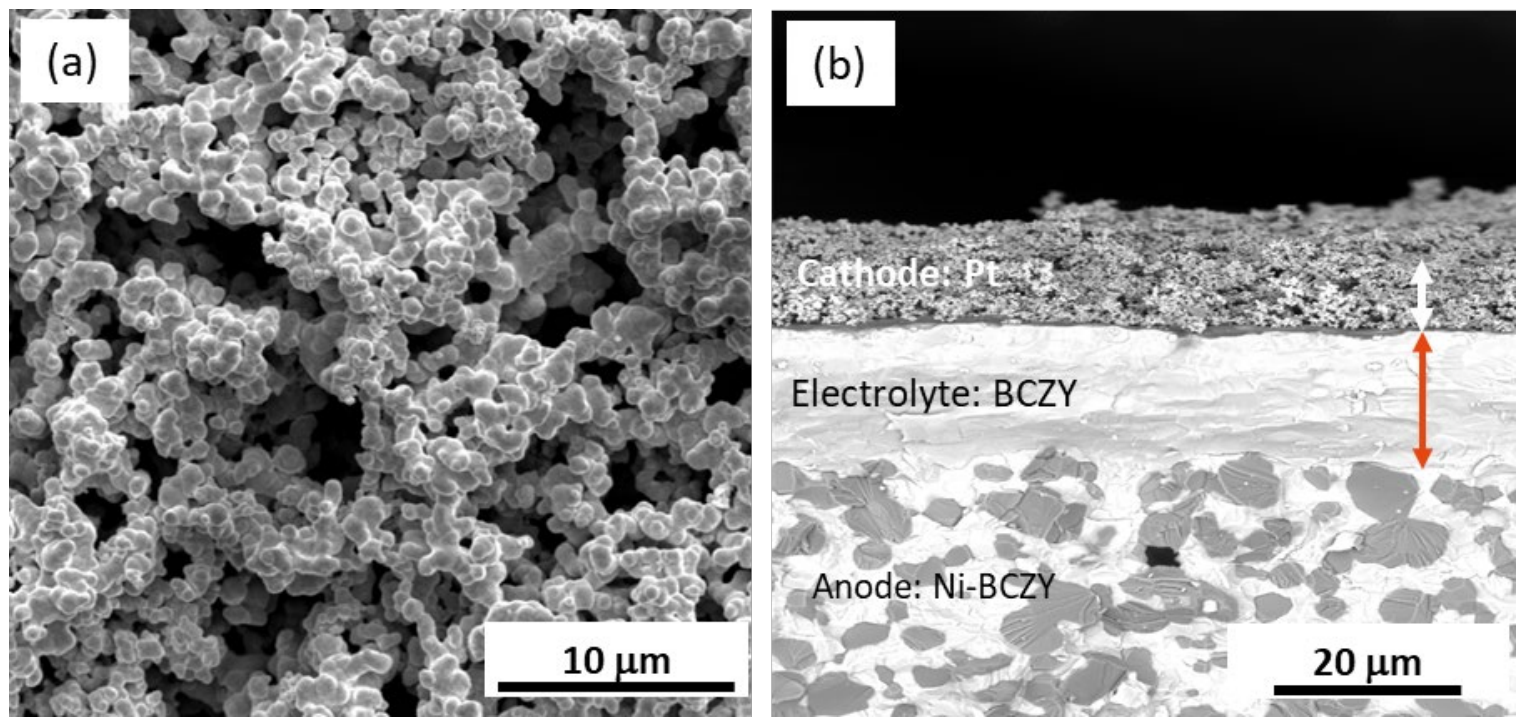

Figure S1: Microstructure (top) of Ni-BCZY/BCZY/Pt cell. Surface view (a) and Cross-section view (b). 


\section{Electrochemical Characterization}

Nyquist plots at $500{ }^{\circ} \mathrm{C}$ with or without plasma are shown in Figure S2. Both the plots are similar. Series resistance which is the high frequency intercept on the real axis, is $2.5 \Omega$. Electrode polarization resistance which is the difference between high frequency and low frequency intercept on the real axis, is around $1250 \Omega$. Electrode polarization resistance can be improved further by optimization of electrode microstructure and architecture. However, this is not the objective of this work.

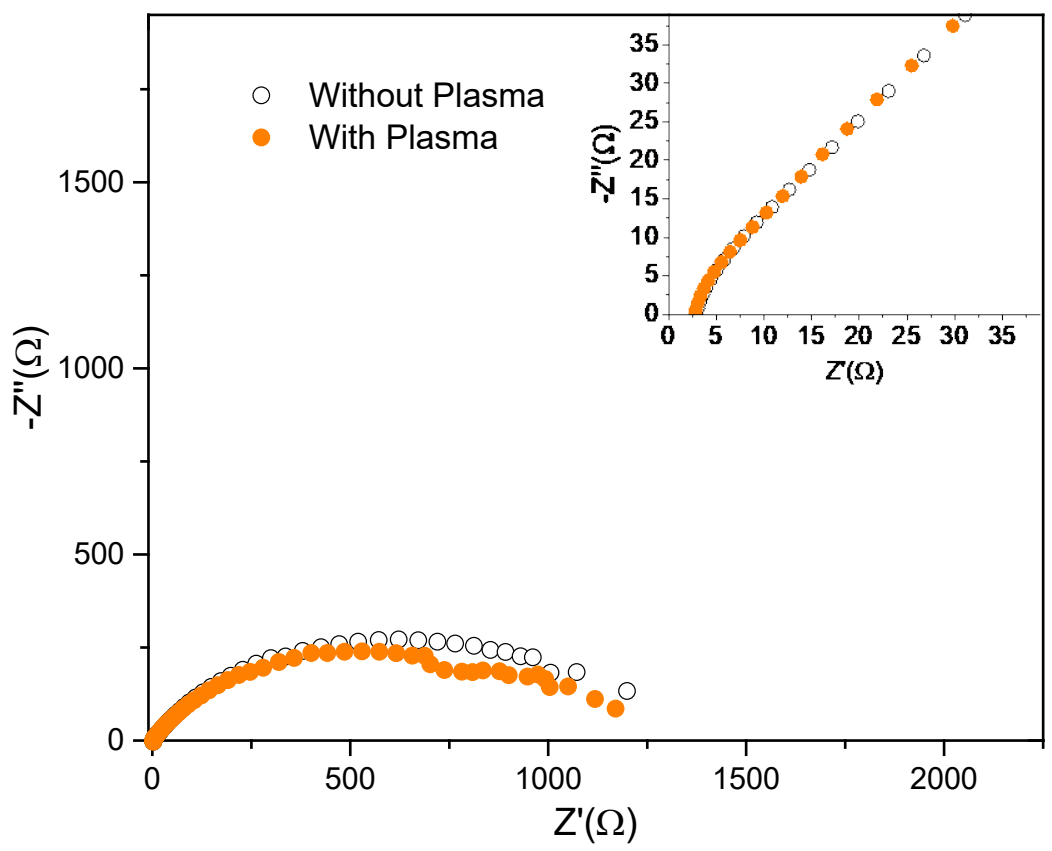

Figure S2: Nyquist plot of Ni-BCZY/BCZY/Pt at OCV at 0 and $80 \mathrm{~W}$ plasma power.

\section{Calculation of the active surface}

Electrochemically active surface area (ECSA) of Pt can be estimated by the well-established method of hydrogen under potential deposition (HUPD) [1]. We have performed HUPD using cyclic voltammetry. For this, a three electrode cell with Pt/YSZ, Pt coil and Ag/AgCl as working, counter and reference electrodes, respectively, has been used at $\mathrm{pH}=1\left(\mathrm{H}_{2} \mathrm{SO}_{4}\right)$. During the 
reduction of $\mathrm{Pt}$, protons from the acid are adsorbed at the surface of the electrode whereas for the oxidation, these atoms of hydrogen are desorbed according to the following electrochemical reaction: $\mathrm{H}_{\mathrm{ad}} \rightarrow \mathrm{H}^{+}+\mathrm{e}^{-}$

Thus the number of electrons liberated during the oxidation of $\mathrm{Pt}$ for low potentials gives the number of hydrogen atoms desorbed and hence the number of adsorption sites present on the electrode's surface. This defines the active surface of the electrode. Cyclic voltammogram for $\mathrm{Pt} / \mathrm{YSZ}$ is shown in Figure S3. The total charge corresponding to the hydrogen desorption can be related to the integral of the curve for a certain interval of potentials $(60$ to $350 \mathrm{mV})$ where the atoms are being desorbed. This charge is $1040 \mathrm{mC}$ for $1 \mathrm{~cm}^{2}$ of Pt electrode and corresponds to $6.5 \times 10^{15}$ adsorption sites (or $4.95 \mathrm{~cm}^{2}$ of Pt surface) per electrode $\mathrm{cm}^{2}$ so for $5 \mathrm{~cm}^{2}$ area it is 3.25 $\mathrm{x} 10^{16}$ which is equal to $52.5 \mathrm{nmol}$ of $\mathrm{Pt}$.

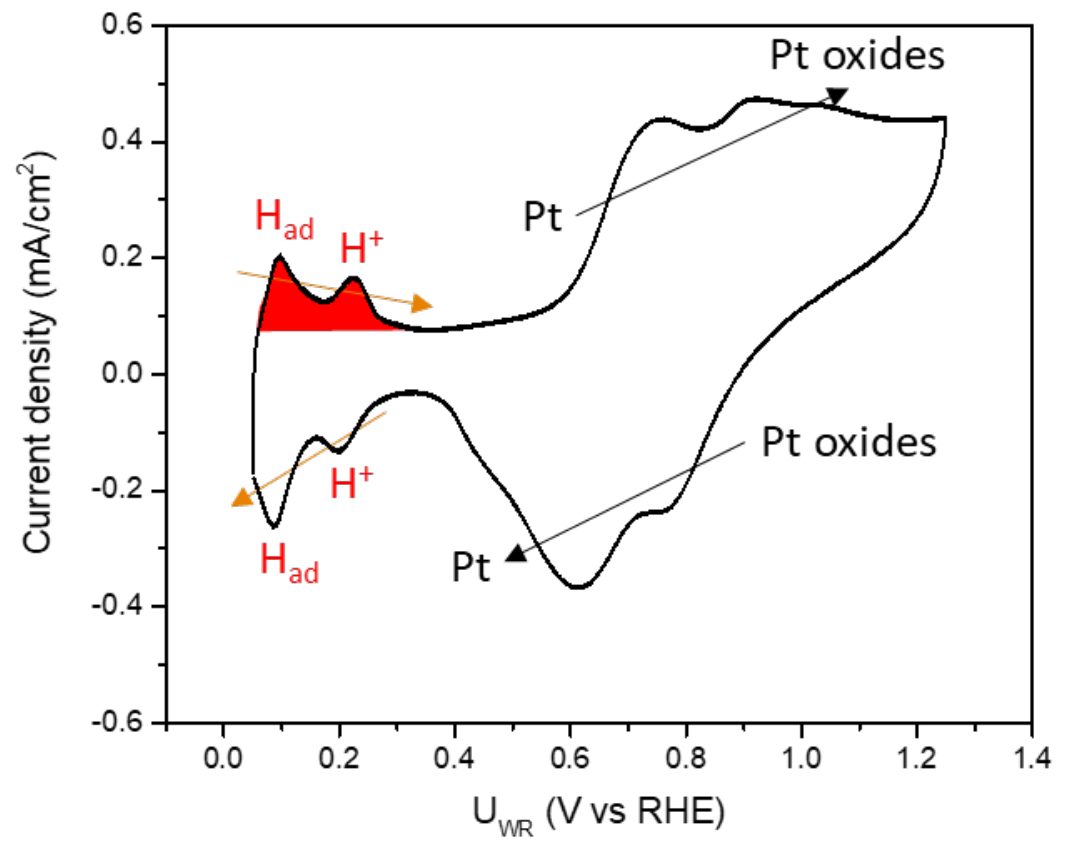

Figure S3: Cyclic voltammetry of $\mathrm{Pt} / \mathrm{YSZ}$ cell for ECSA determination, $\left(\mathrm{H}_{2} \mathrm{SO}_{4} \mathrm{pH}=1\right.$, scan rate $15 \mathrm{mV} / \mathrm{s})$. 


\section{Calculation of the turn over frequency (TOF)}

Turn over frequency (reaction rate per catalytic active site) as function of current is shown in figure S4. TOF for the current density $80 \mathrm{~mA} / \mathrm{cm}^{2}$ is $2.55 \mathrm{~s}^{-1}$.

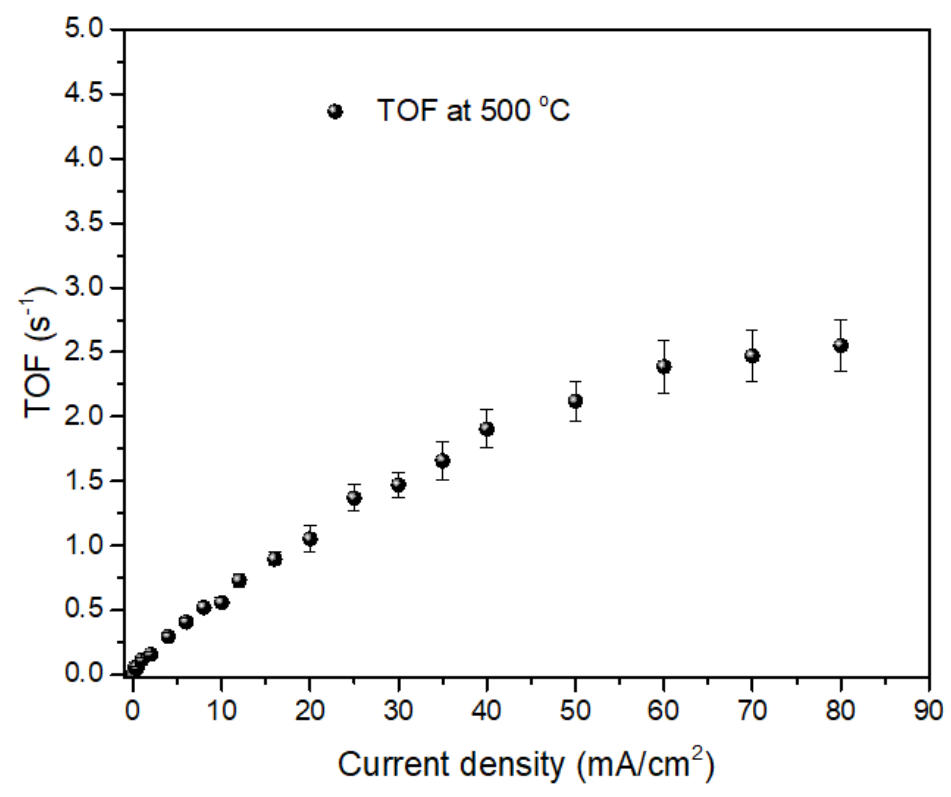

Figure S4: Turn over frequency (TOF) as a function of current density.

\section{Effect of the plasma power on $\mathrm{NH}_{3}$ synthesis}

Figure $\mathrm{S} 5$ shows the effect of plasma power on $\mathrm{NH}_{3}$ concentration for applied current $120 \mathrm{~mA}$ at $500{ }^{\circ} \mathrm{C}$. As shown in this figure, $\mathrm{NH}_{3}$ concentration increases with plasma power. $\mathrm{NH}_{3}$ concentration values 352, 656, 1075 and $915 \mathrm{ppm}$ have been observed for the plasma power 40 , 60,80 and $120 \mathrm{~W}$, respectively. However, at $120 \mathrm{~W}, \mathrm{NH}_{3}$ is lower.

To analyze this further, plasma length and plasma radius were estimated from the photographs in Figure S5, see Table S1. From this it is revealed that the power density is approximately constant, varying between $0.57-0.66 \mathrm{~W} / \mathrm{cm}^{3}$. For an applied frequency of $13.56 \mathrm{MHz}$, at a gas pressure of 5 mbar, electron density can be expected to be low enough that the radial electric field amplitude 
generated by the coils is not significantly affected by the presence of plasma [2]. In other words, the skin depth of the applied electric field is very large compared to the radius of the plasma, thus there is limited variation of electric field within the plasma volume and it can also be expected that plasma power density is relatively constant within the volume.

Furthermore, based on self-consistent kinetic models by Guerra et al. at conditions similar to those used here, a reduced electric field of $\sim 50 \mathrm{Td}$ can be assumed for $\mathrm{N}_{2}$ plasma at a pressure of $5 \mathrm{mbar}$ [3]. A further check of this reduced electric field can be made by determining the electron density required to achieve the estimated power density obtained from the photographs. At $50 \mathrm{Td}$ in a pure $\mathrm{N}_{2}$ gas at an estimated gas temperature of $\sim 800 \mathrm{~K}$, each electron can transfer $2.3 \cdot 10^{-11} \mathrm{~W}$ to $\mathrm{N}_{2}$ molecules, as calculated using a Boltzmann solver in pure $\mathrm{N}_{2}[4,5]$. The electron density must then be $0.6 / 2.3 \cdot 10^{-11}=2.6 \cdot 10^{10} \mathrm{~cm}^{-3}$; a value consistent with that obtained in the self-consistent models of similar $\mathrm{N}_{2}$ plasmas [3], and equally consistent with a large skin depth for the applied electric field [2].

Based on the above discussion, it can be concluded that the largest difference in conditions between different plasma powers comes from the growth of the plasma volume and the corresponding reduction of the distance between the plasma edge and the electrolyser surface. This distance can also be estimated from the photographs in Figure S5. If it is further assumed that the axial gas flow velocity profile is relatively flat along the tube cross-section, these distances can be easily converted to an average time-of-flight for plasma-activated nitrogen species towards the electrolyser surface. For a flow rate of $100 \mathrm{sccm}$ at $5 \mathrm{mbar}$ and an estimated gas temperature of $800 \mathrm{~K}$ the average gas flow velocity is $0.88 \mathrm{~m} / \mathrm{s}$, leading to time-of-flight between 122 and $188 \mathrm{~ms}$ (see Table S1). 
Table S1: Estimated plasma sizes, power density, distance to surface, time-of-flight and electron density as function of plasma power. The calculation for time-of-flight assumes an axial gas flow velocity of $0.88 \mathrm{~m} / \mathrm{s}$ and expected electron density is based on a power dissipation of $2.3 \cdot 10^{10}$ W/electron.

\begin{tabular}{|c|c|c|c|c|c|c|}
\hline $\begin{array}{c}\text { Plasma } \\
\text { power }(\mathbf{W})\end{array}$ & $\begin{array}{c}\text { Estimated } \\
\text { length } \mathbf{( c m )}\end{array}$ & $\begin{array}{c}\text { Estimated } \\
\text { radius } \mathbf{( c m )}\end{array}$ & $\begin{array}{c}\text { Power } \\
\text { density } \\
\left(\mathbf{W} / \mathbf{c m}^{\mathbf{3}}\right)\end{array}$ & $\begin{array}{c}\text { Estimated } \\
\text { distance to } \\
\text { surface } \mathbf{( c m )}\end{array}$ & $\begin{array}{c}\text { Time-of- } \\
\text { flight to } \\
\text { surface }(\mathbf{s})\end{array}$ & $\begin{array}{c}\text { Expected } \\
\text { electron density } \\
\mathbf{( 1 0}^{\mathbf{1 0}} \mathbf{c m}^{\mathbf{3}} \mathbf{)}\end{array}$ \\
\hline 40 & 9.35 & 1.50 & 0.61 & 16.6 & 0.188 & 2.62 \\
\hline 60 & 12.9 & 1.31 & 0.57 & 14.8 & 0.168 & 2.46 \\
\hline 80 & 15.4 & 1.68 & 0.58 & 12.8 & 0.145 & 2.51 \\
\hline 120 & 19.1 & 1.74 & 0.66 & 10.8 & 0.122 & 2.84 \\
\hline
\end{tabular}
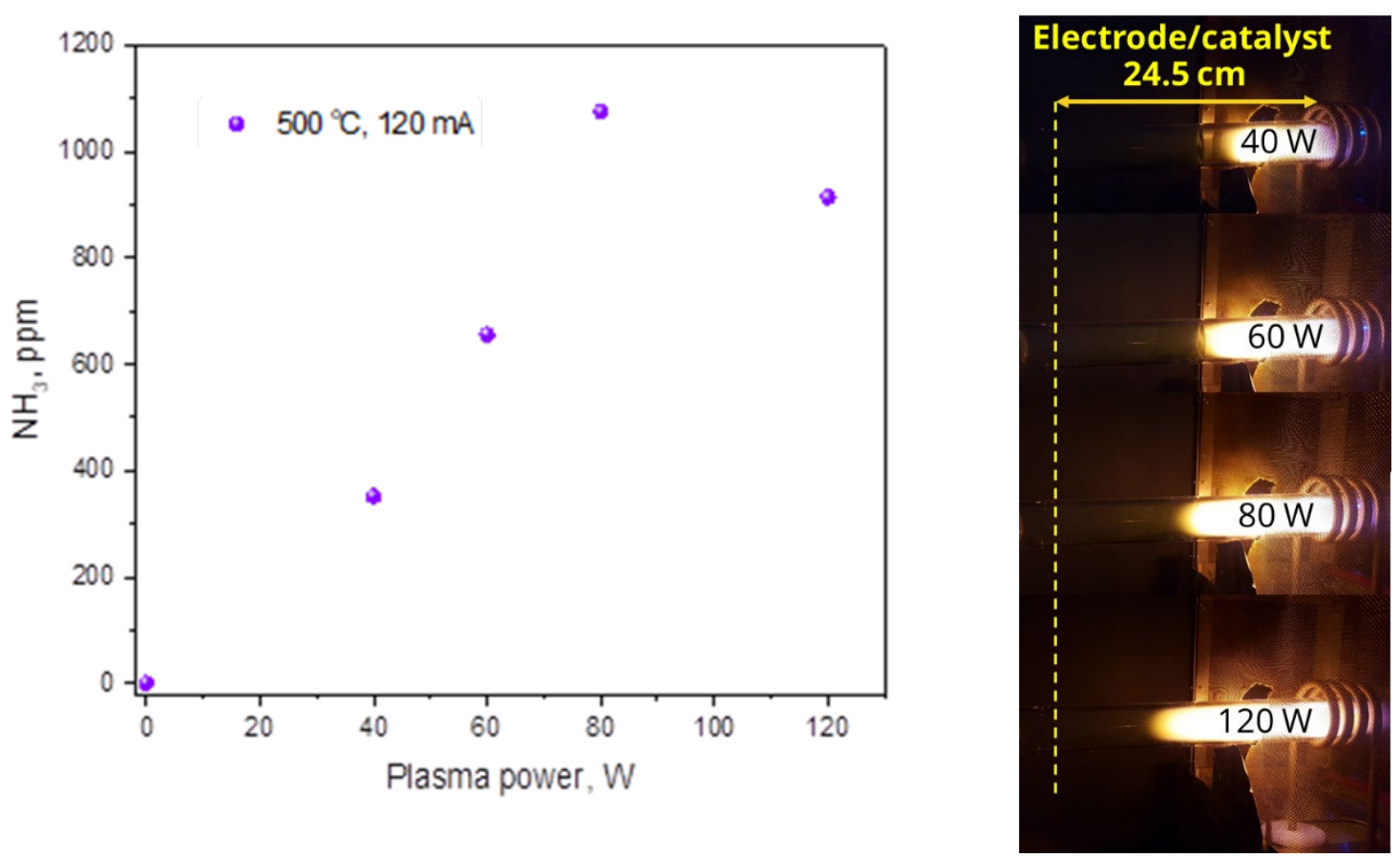

Figure S5: Effect of plasma power on the concentration of $\mathrm{NH}_{3}$ (left) and picture of $\mathrm{N}_{2}$ plasma with different power (right). 
Ammonia formation increases as the plasma power is increased except from the case of $120 \mathrm{~W}$ ( Figure S5). There could be one of the two potential reasons for the poorer performance at $120 \mathrm{~W}$ compared to $80 \mathrm{~W}$. The first one is the larger plasma diameter at $120 \mathrm{~W}$. As a consequence, plasma is almost in direct contact with the quartz tube wall at this higher power which leads to more atomic $\mathrm{N}$ recombination, and relaxation of vibrationally excited $\mathrm{N}_{2}$ on this surface prior to reaching the electrolyser [6]. The second potential reason is related to the distribution of vibrational energy among nitrogen molecules. In fact, as per the vibrational ladder climbing effect, vibrational energy tends to accumulate in the most highly excited collision partner during the collisions between vibrationally excited $\mathrm{N}_{2}$. However, for $120 \mathrm{~W}$ plasma, the time-of-flight of plasma-activated $\mathrm{N}_{2}$ to the surface is the shortest (Table S1), and hence the least ladder climbing effect will have occured [3]. Therefore, for reaction at the electrode surface which requires a certain minimum vibrational energy in $\mathrm{N}_{2}$, a longer time-of-flight (i.e. a lower plasma power) may lead to a higher ammonia production.

\section{Pure plasma and plasma catalysis approaches}

The ammonia production in pure plasma (without catalyst) and plasma assisted catalysis (on Pt catalyst of Ni-BCZY/BCZY/Pt cell) have been carried out at $500{ }^{\circ} \mathrm{C}$, where the reactants $\left(\mathrm{H}_{2}\right.$ and $\mathrm{N}_{2}$ ) were co-activated by RF- plasma, as shown schematically in Figure 4 S6 (top). Here, the reaction rate is not normalized to the surface area since the pure plasma constitutes a process reactor wall not in a well-defined way and hence, it is not possible to define the catalytically active area. Ammonia rates as high as 78 and $90 \mathrm{nmol} / \mathrm{s}$ have been obtained for pure plasma and plasma assisted processes, respectively (Figure S6). Therefore, only a small contribution of Pt catalyst to $\mathrm{NH}_{3}$ formation is observed under this operation mode where nitrogen and hydrogen are both 
activated in the plasma. The overall trend of $\mathrm{NH}_{3}$ concentration with increasing $\mathrm{H}_{2}$ fraction in the gas-phase does not change with the introduction of the Pt catalyst which is consistent with literature. As per literature, for pure plasma catalysis, it is mostly the available surface area that participates in ammonia synthesis and introduction of a small additional surface area of Pt only enhances the $\mathrm{NH}_{3}$ production without significantly shifting the optimal hydrogen/nitrogen ratio [7-9].

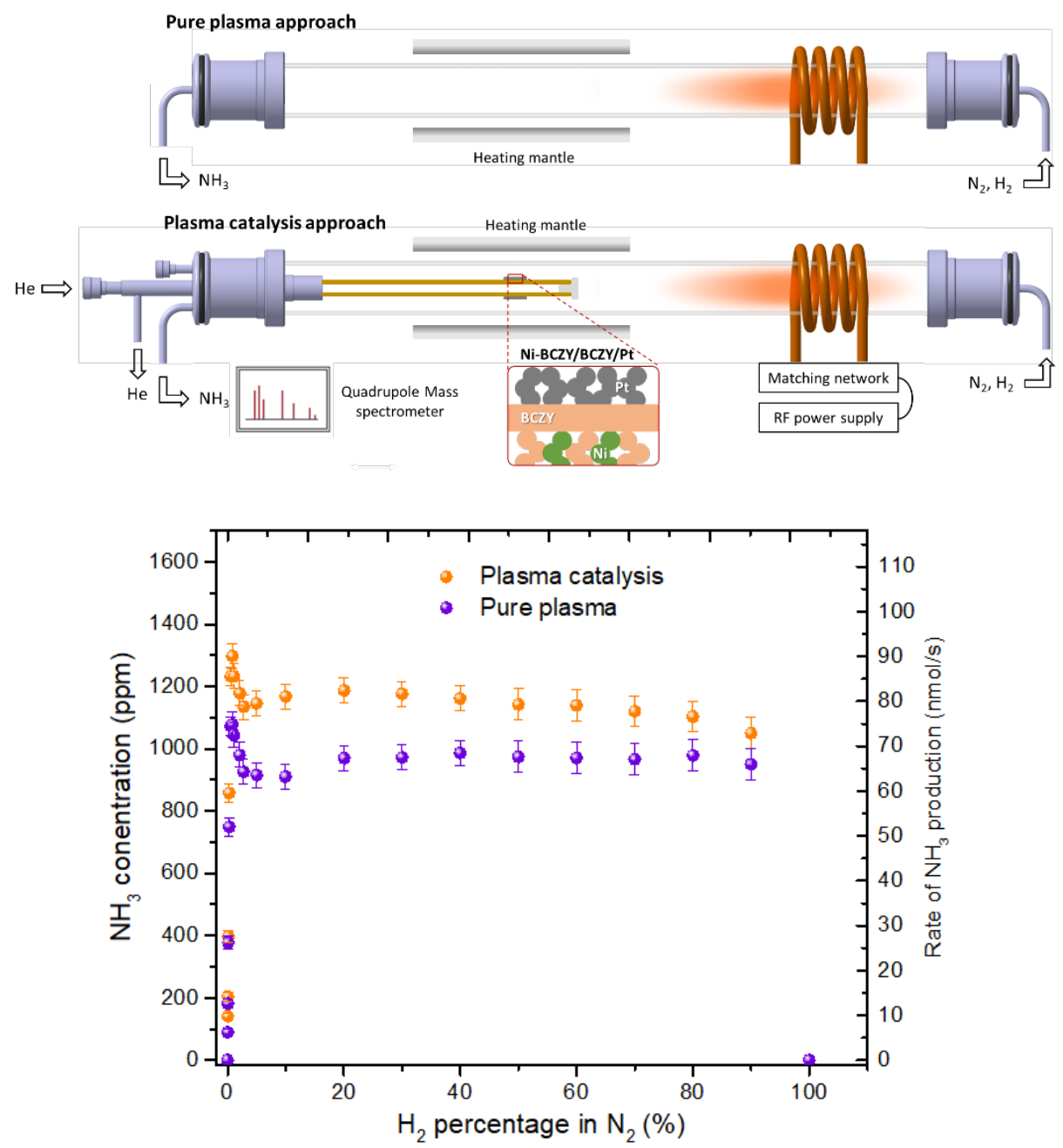

Figure S6. Pure plasma vs. plasma catalysis (on Pt electrode of cell), schematic (top) and ammonia formation (bottom). 
An interesting fact is that the maximum ammonia formation is obtained for low hydrogen/nitrogen ratios. This also corroborates to the coupling of nitrogen plasmas with water electrolysers (at these specific conditions) in a single reactor as proposed here since electrolysers can operate up to a specific current density (i.e. $\sim 0.5-1 \mathrm{~A} / \mathrm{cm}^{2}$ ) which typically correspond to the equivalent hydrogen flux of the same percentage range $\left(\sim 3 \% \mathrm{H}_{2}\right)$ required to obtain the optimal ammonia formation rate.

\section{Equilibrium concentration of ammonia}

Figure $\mathrm{S} 7$ shows the equilibrium concentration of $\mathrm{NH}_{3}$ in $\mathrm{N}_{2}, \mathrm{H}_{2}, \mathrm{NH}_{3}$ mixture as a function of as a function of temperature and pressure for $3 \% \mathrm{H}_{2}$ in $\mathrm{N}_{2}$. The thermodynamic calculations were performed at this composition to simulate the gas mixture obtained upon at the conditions ( 80 $\mathrm{mA} / \mathrm{cm}^{2}$ of protonic flux and $100 \mathrm{sccm}$ of total flow rate) where the highest ammonia production rate was observed. With increasing temperature, $\mathrm{NH}_{3}$ concentration is decreasing whereas at temperature in between $200-800{ }^{\circ} \mathrm{C}$, it is increasing with pressure.

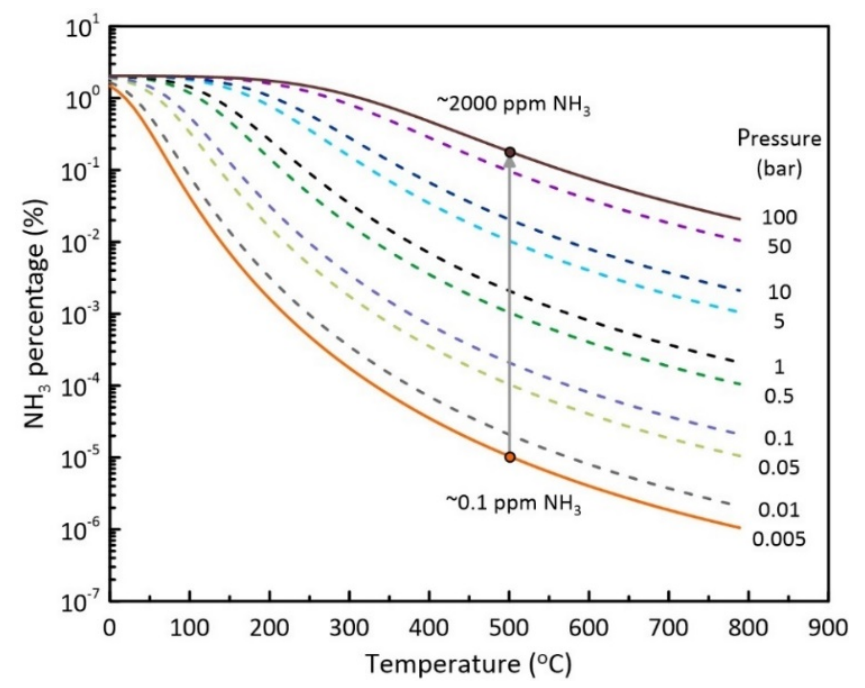

Figure S7. Equilibrium concentration of $\mathrm{NH}_{3}$ as a function of the Temperature and pressure for $3 \% \mathrm{H}_{2}$ in $\mathrm{N}_{2}$. 


\section{Benchmarking our approach with electrochemical ammonia synthesis: Present study vs.}

\section{literature}

Present study has been compared with literature. As shown in Figure S8a and b, both $\mathrm{NH}_{3}$ formation rate and corresponding faradaic efficiency is much higher than reported values in literature.
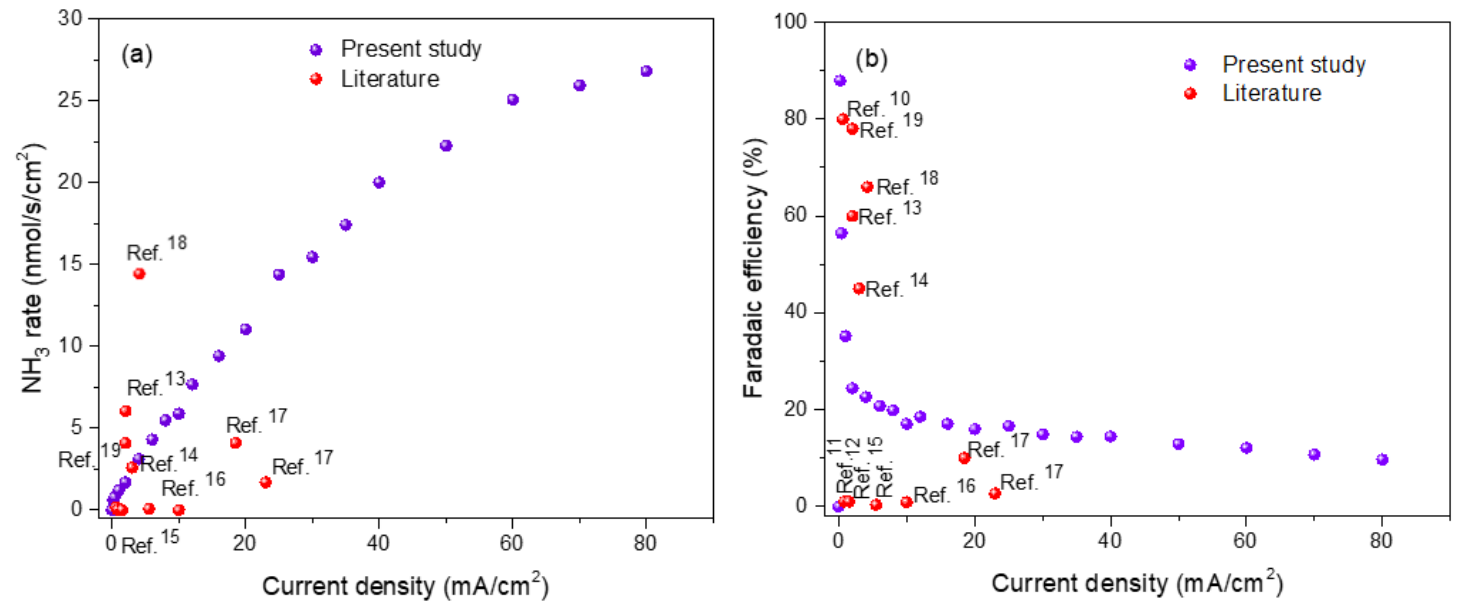

Figure S8: Present study vs. literature [10-19]. $\mathrm{NH}_{3}$ rate (a) and Faradaic efficiency (b).

\section{REFERENCES}

[1] Łukaszewski, M.; Soszko, M.; Czerwinski, A. Electrochemical methods of real surface area determination of noble metal electrodes-an overview. Int. J. Electrochem. Sci. 2016, 11, $4442-4469$.

[2] Lieberman, M. A.; Lichtenberg, A. J. Principles of plasma discharges and materials processing, Chapter 12. John Wiley \& Sons, Inc., New York, 1994.

[3] Guerra, V.; Sá, P. A.; Loureiro, J. Electron and metastable kinetics in the nitrogen afterglow. Plasma sources science and technology 2003, 12(4), S8-S15. 
[4] Hagelaar, G. J. M.; Pitchford, L. C. Solving the Boltzmann equation to obtain electron transport coefficients and rate coefficients for fluid models. Plasma Sources Science and Technology 2005, 14(4), 722-733.

[5] Biagi-v7.1 database, www.lxcat.net, retrieved on August 28, 2020.

[6] Es-Sebbar, E.; Benilan, Y.; Jolly, A.; Gazeau, M. C. Characterization of an $\mathrm{N}_{2}$ flowing microwave post-discharge by OES spectroscopy and determination of absolute ground-state nitrogen atom densities by TALIF. Journal of Physics D: Applied Physics 2009, 42(13), 135206-135217.

[7] Shah, J.; Wang, W.; Bogaerts, A.; Carreon, M. L. Ammonia synthesis by radio frequency plasma catalysis: revealing the underlying mechanisms. ACS Applied Energy Materials 2018, 1 (9), 4824-4839.

[8] Van Helden, J.; Wagemans, W.; Yagci, G.; Zijlmans, R.; Schram, D.; Engeln, R.; Lombardi, G.; Stancu, G.; Röpcke, J. Detailed Study of the Plasma-Activated Catalytic Generation of Ammonia in $\mathrm{N}_{2}-\mathrm{H}_{2}$ Plasmas. J. Appl. Phys. 2007, 101, 043305-043316.

[9] Carrasco, E.; Jiménez-Redondo, M.; Tanarro, I.; Herrero, V. J. Neutral and ion chemistry in low pressure de plasmas of $\mathrm{H}_{2} / \mathrm{N}_{2}$ mixtures: routes for the efficient production of $\mathrm{NH}_{3}$ and $\mathrm{NH}_{4}{ }^{+}$. Physical Chemistry Chemical Physics 2011, 13(43), 19561-19572.

[10] Xie, Y.H.; Wang, J.D.; Liu, R.Q.; Su, X.T.; Sun, Z.P.; Li, Z.J. Preparation of $\mathrm{La}_{1.9} \mathrm{Ca}_{0}$. ${ }_{1} \mathrm{Zr}_{2} \mathrm{O}_{6.95}$ with pyrochlore structure and its application in synthesis of ammonia at atmospheric pressure. Solid State Ion. 2004, 168, 117-121. 
[11] Otomo, J.; Noda, N.; Kosaka, F. Electrochemical synthesis of ammonia with proton conducting solid electrolyte fuel cells at intermediate temperatures. ECS Trans. 2015, 68, $2663-2670$.

[12] Ouzounidou, M.; Skodra, A.; Kokkofitis, C.; Stoukides, M. Catalytic and electrocatalytic synthesis of $\mathrm{NH}_{3}$ in a $\mathrm{H}^{+}$conducting cell by using an industrial Fe catalyst. Solid State Ion. 2007, 178, 153-159.

[13] Wang, W.B.; Cao, X.B.; Gao, W.J.; Zhang, F.; Wang, H.T.; Ma, G.L. Ammonia synthesis at atmospheric pressure using a reactor with thin solid electrolyte $\mathrm{BaCe}_{0.85} \mathrm{Y}_{0.15} \mathrm{O}_{3-\alpha}$ membrane. J. Membr. Sci. 2010, 360, 397-403.

[14] Zhang, M.; Xu, J.; Ma, G. Proton conduction in BaxCe $\mathrm{B}_{0.8} \mathrm{Y}_{0.2} \mathrm{O}_{3-\alpha}+0.04 \mathrm{ZnO}$ at intermediate temperatures and its application in ammonia synthesis at atmospheric pressure. J. Mater. Sci. $2011,46,4690-4694$.

[15] Yun, D.S.; Joo, J.H.; Yu, J.H.; Yoon, H.C.; Kim, J.N.; Yoo, C.Y. Electrochemical ammonia synthesis from steam and nitrogen using proton conducting yttrium doped barium zirconate electrolyte with silver, platinum, and lanthanum strontium cobalt ferrite electrocatalyst. J. Power Sources 2015, 284, 245-251.

[16] Skodra, A.; Stoukides, M. Electrocatalytic synthesis of ammonia from steam and nitrogen at atmospheric pressure. Solid State Ion. 2009, 180, 1332-1336.

[17] Vasileiou, E.; Kyriakou, V.; Garagounis, I.; Vourros, A.; Manerbino, A.; Coors, W.G.; Stoukides, M. Electrochemical enhancement of ammonia synthesis in a $\mathrm{BaZr}_{0.7} \mathrm{Ce}_{0.2} \mathrm{Y}_{0.1} \mathrm{O}_{2.9}$ solid electrolyte cell. Solid State Ion. 2016, 288, 357-362. 
[18] Hao, Y.C.; Guo, Y.; Chen, L.W.; Shu, M.; Wang, X.Y.; Bu, T.A.; Gao, W.Y.; Zhang, N.; Su, X.; Feng, X; Zhou, J.W. Promoting nitrogen electroreduction to ammonia with bismuth nanocrystals and potassium cations in water. Nature Catalysis 2019, 2(5), 448-456.

[19] Marnellos, G.; Stoukides, M., Ammonia synthesis at atmospheric pressure, Science, 1998, 282, 98100. 